\title{
Motion of the dayside polar cap boundary during substorm cycles: I. Observations of pulses in the magnetopause reconnection rate
}

\author{
M. Lockwood ${ }^{1, *}$, J. Moen ${ }^{2, * *}$, A. P. van Eyken ${ }^{3}$, J. A. Davies ${ }^{1}$, K. Oksavik ${ }^{2, * * *}$, and I. W. McCrea ${ }^{1}$ \\ ${ }^{1}$ Rutherford Appleton Laboratory, Chilton, Didcot, Oxon OX11 0QX, UK \\ ${ }^{2}$ Department of Physics, University of Oslo, P.O. Box 1048 Blindern, N-0316 Oslo, Norway \\ ${ }^{3}$ EISCAT Headquarters, Kiruna, Sweden \\ *also at: Department of Physics and Astronomy, Southampton University, Southampton, Hampshire, UK \\ ** also at: Arctic Geophysics, University Centre on Svalbard, N-9170 Longyearbyen, Norway \\ ****also at: Johns Hopkins University, Applied Physics Laboratory, Laurel, MD, USA
}

Received: 11 July 2003 - Revised: 12 October 2005 - Accepted: 20 October 2005 - Published: 21 December 2005

\begin{abstract}
Using data from the EISCAT (European Incoherent Scatter) VHF radar and DMSP (Defense Meteorological Satellite Program) spacecraft passes, we study the motion of the dayside open-closed field line boundary during two substorm cycles. The satellite data show that the motions of ion and electron temperature boundaries in EISCAT data, as reported by Moen et al. (2004), are not localised around the radar; rather, they reflect motions of the open-closed field line boundary at all MLT throughout the dayside auroral ionosphere. The boundary is shown to erode equatorward when the IMF points southward, consistent with the effect of magnetopause reconnection. During the substorm expansion and recovery phases, the dayside boundary returns poleward, whether the IMF points northward or southward. However, the poleward retreat was much faster during the substorm for which the IMF had returned to northward than for the substorm for which the IMF remained southward - even though the former substorm is much the weaker of the two. These poleward retreats are consistent with the destruction of open flux at the tail current sheet. Application of a new analysis of the peak ion energies at the equatorward edge of the cleft/cusp/mantle dispersion seen by the DMSP satellites identifies the dayside reconnection merging gap to extend in MLT from about 9.5 to $15.5 \mathrm{~h}$ for most of the interval. Analysis of the boundary motion, and of the convection velocities seen near the boundary by EISCAT, allows calculation of the reconnection rate (mapped down to the ionosphere) from the flow component normal to the boundary in its own rest frame. This reconnection rate is not, in general, significantly different from zero before 06:45 UT (MLT $<9.5 \mathrm{~h}$ ) indicating that the $\mathrm{X}$ line footprint expands over the EISCAT field-of-view to earlier MLT only occasionally and briefly. Between 06:45 UT and 12:45UT $(9.5<$ MLT $<15.5 \mathrm{~h})$ reconnection is continuously observed by EISCAT, confirming the
\end{abstract}

Correspondence to: M. Lockwood

(m.lockwood@rl.ac.uk) (large) MLT extent of the reconnection footprint deduced from the DMSP passes. As well as direct control by the IMF on longer timescales, the derived reconnection rate variation shows considerable pulsing on timescales of 2-20 min during periods of steady southward IMF.

Keywords. Ionosphere (Polar ionosphere) - Magnetospheric physics (Magnetopause, cusp and boundary layers; Storms and substorms)

\section{Introduction}

In a previous paper, Moen et al. (2004) studied various signatures of the dayside auroral oval, as seen by the EISCAT (European Incoherent Scatter) VHF incoherent scatter radar on 23 November 1999, with a view to evaluating the best identifier of the open-closed field line boundary (hereafter referred to as the OCB). In this paper, we make use of their results to study the behaviour of the OCB during two successive substorm cycles on this day. In a separate study of the same interval, Davies et al. (2002) reported poleward-moving plasma concentration enhancements ("patches") seen by EISCAT and by the CUTLASS $\mathrm{HF}$ radar at Hankasami. In the present paper, we analyse the boundary motions in terms of the reconnection rate variations, at the dayside magnetopause and in the tail current sheet. In an accompanying paper (Lockwood et al., 2005, hereafter referred to as Paper II), we study the association of reconnection rate pulses with the formation of the polar cap patches.

1.1 Predicted open-closed boundary motions during the substorm cycle

In the growth phase of a substorm, the total rate at which closed flux is opened by reconnection at the dayside 
magnetopause $\Phi_{D}$ exceeds the total rate at which open flux is closed by reconnection in the nightside tail $\Phi_{N}$. By Faraday's induction law, $\Phi_{D}$ and $\Phi_{N}$ are the total reconnection voltages associated with, respectively, the opening and closing of flux tubes. As a result, the open flux $\mathrm{F}_{p c}$ increases according to the continuity equation (Siscoe and Huang, 1985; Moses et al., 1989; Lockwood et al., 1990; Lockwood and Cowley, 1992; Cowley and Lockwood, 1992)):

$\Phi_{D}-\Phi_{N}=d F_{p c} / d t=B_{i} d A_{p c} / d t$.

The ionospheric field $B_{i}$ can be considered constant because the ionosphere is "incompressible" (in the sense that $B_{i}=5 \times 10^{-5} \mathrm{~T}$ to within of order $1 \%$ ). In this paper we define the term "polar cap" to mean the region of open flux. From Eq. (1), when $\Phi_{D}$ exceeds $\Phi_{N}$ the polar cap area, $A_{p c}=F_{p c} / B_{i}$, increases and these intervals are called substorm growth phases. In the expansion phase and most of the recovery phase of the subsequent substorm, $\Phi_{D}<\Phi_{N}$ and by Eq. (1), $F_{p c}$ and $A_{p c}$ both decrease again.

How the dayside segment of the open-closed boundary (OCB) behaves during substorm cycles gives us information about how the shape of the polar cap varies as it expands and contracts. In the illustrative concepts introduced by Siscoe and Huang (1985), the polar cap was assumed to be circular at all times, in which case the boundary motions would be the same throughout the dayside as well as on the nightside. The behaviour of the polar cap shape is a key factor determining the global, time-dependent convection response of the ionosphere to changes in the magnetopause reconnection rate. Freeman (2003) adopted the same assumption as Siscoe and Huang, whereas Lockwood and Morley (2004) included the perturbations to the shape of the polar cap proposed by Cowley and Lockwood $(1992,1997)$.

Expansion and contraction of the polar cap during substorm cycles has been reported in many observations (Akasofu et al., 1992; Frank and Craven, 1988; Moses et al., 1989; Lester at al., 1990; Milan et al., 2003). Several of these studies employed global UV images and identified the OCB with the poleward edge of the auroral oval seen in UV: this can substantially overestimate $\mathrm{A}_{p c}$ because the true OCB can lie considerably poleward of the poleward edge of the detectable aurora. This is particularly true on the nightside but also applies, to a lesser extent, on the dayside (Elphinstone et al., 1992). Indeed, even with in-situ particle data, the OCB definition can be difficult (Lockwood, 1997a; 1998; Oksavik et al., 2000).

1.2 Observations interpreted as dayside open-closed boundary motions during the substorm cycle

Burch (1973) observed the equatorward motion of the cusp precipitation for increasingly southward IMF and associated this motion with the Earthward erosion of the magnetopause caused by reconnection (Aubry, 1970). Statistically, the cusp latitude has been shown to be a function of both the IMF $B_{z}$ component and the auroral electrojet $A E$ index (Carbary and
Meng, 1988; Aparicio et al., 1991), showing an additional dependence on the processes in the geomagnetic tail.

The dayside 630-nm red-line aurora, associated with cusp/cleft magnetosheath electron precipitation, was also found to migrate equatorward after the IMF turned southward and return poleward when the IMF turned northward and/or during a substorm expansion phase (Vorobjev et al., 1975; Horwitz and Akasofu, 1977; Eather et al., 1979; Rezhenov et al., 1979; Eather, 1985; Sandholt et al., 1983; 1998; Sandholt, 1988). McCrea et al. (2000) showed that the motions of the 630-nm aurora were matched by those of a band of enhanced electron temperature, as observed by the EISCAT VHF radar. Such boundary motions have also recently been reported in the Doppler-shifted Lyman- $\alpha$ emissions due to cusp proton precipitation (Lockwood et al., 2003). Freeman and Southwood (1988) observed enhanced flows consistent with the equatorward erosion of the dayside OCB during an interval when inward magnetopause erosion was observed. Lockwood et al. (1993b) reported a series of equatorward migrations of the dayside boundary that occurred in association with transient convection enhancements which they also interpreted as the effect of transient reconnection pulses.

\section{Observations}

In this section, we consider observations made on 23 November 1999, between 03:00 and 13:00 UT, by the Wind and ACE satellites in the interplanetary medium, by the EISCAT VHF radar, by the auroral electrojet magnetometers and by various DMSP (Defense Meteorological Satellite Program) spacecraft.

\subsection{Interplanetary monitor data}

Figure 1 is an overview of the Interplanetary Magnetic Field (IMF) and solar wind data on 23 November 1999. We use data from the ACE and Wind spacecraft to predict the propagation delay between both satellites and the dayside magnetopause, employing the procedure given in detail by Lockwood et al. (2003). The variations in all three IMF components were very similar at the two craft despite the fact that ACE was near the Lagrange L1 point, whereas Wind was on the dawn flank of the magnetosphere; for example at 10:00 UT, Wind was at $(\mathrm{X}, \mathrm{Y}, \mathrm{Z})$ of $(-10.3,-59.9,33.9) R_{E}$ in GSE coordinates. As discussed by Davies et al. (2002), the two spacecraft observed almost identical variations in all three IMF components, with a lag between ACE and Wind that is close to $60 \mathrm{~min}$ throughout the period. This implies that the changes in the IMF are all large-scale and oriented at about $18^{\circ}$ with respect to the $\mathrm{Y}$ axis in the $\mathrm{XY}$ plane. Using this orientation, we derive a lag between Wind and the dayside magnetopause of $-3 \min$ (i.e. Wind sees the change $3 \mathrm{~min}$ after the dayside magnetopause). The top 3 panels of Fig. 1 give the $B_{X}, B_{Y}$ and $B_{Z}$ components of the IMF in GSM coordinates, as seen by Wind. At all times, these are 

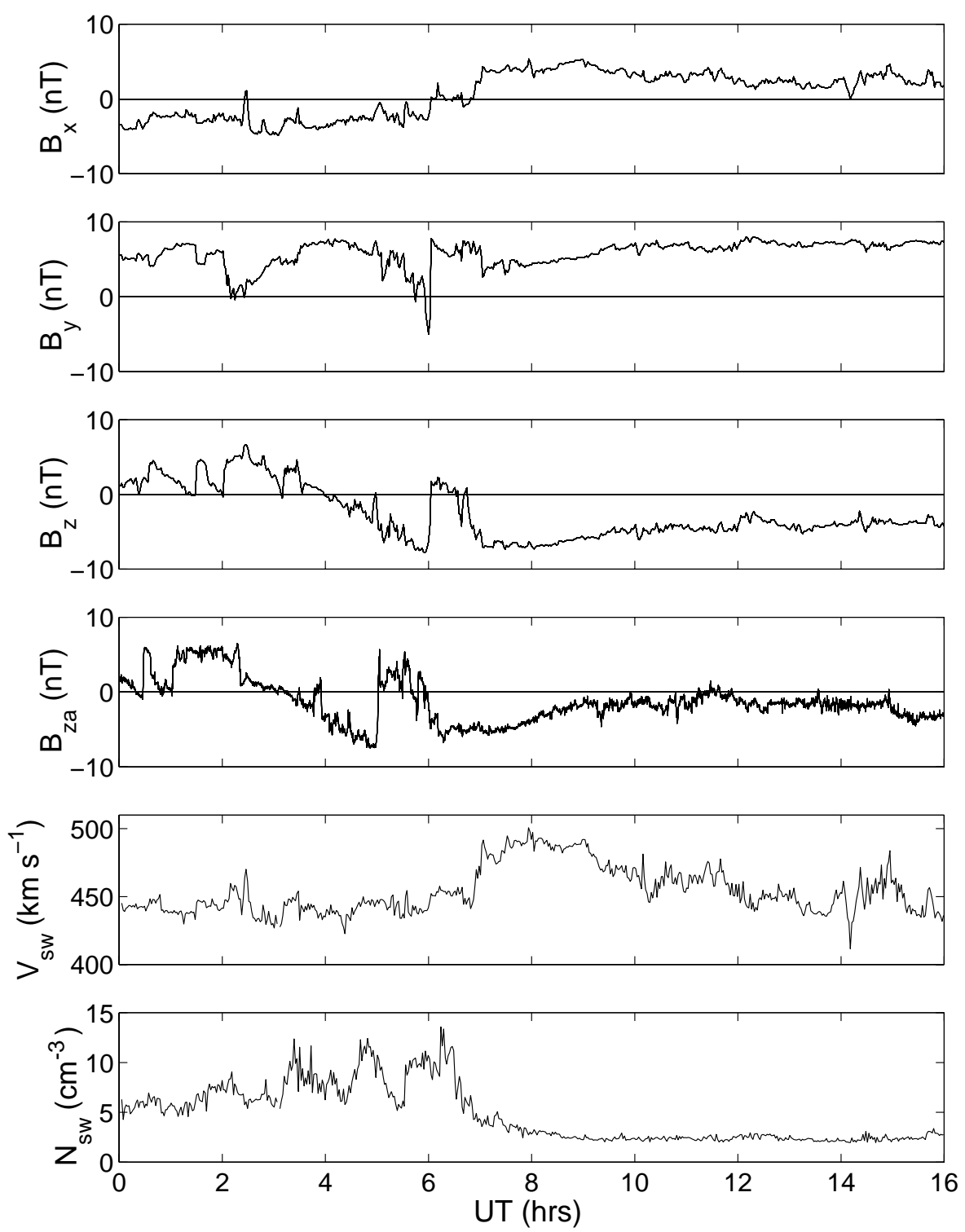

Fig. 1. Summary of solar wind and Interplanetary Magnetic Field (IMF) observations on 23 November 1999. From top to bottom: the IMF components $B_{X}, B_{Y}$ and $B_{Z}$ in the GSM coordinate system, observed by the WIND spacecraft; $B_{Z}$ in the GSE frame observed by the ACE spacecraft; the solar wind speed, $V_{S W}$, and concentration, $N_{S W}$, observed by Wind.

almost identical to the corresponding components seen an hour earlier by ACE (data presented in Fig. 1 of Moen et al., 2004). The fourth panel shows the $B_{Z}$ component of the IMF in GSE coordinates, as seen by ACE, and the lower two panels show the solar wind speed $V_{S W}$ and concentration $N_{S W}$ seen by Wind.

Figure 1 shows that the IMF turned southward at about 04:00 UT at Wind (and almost simultaneously at Earth's dayside magnetopause) and grew increasingly southward until about 06:00 UT when it turned abruptly northward before returning to consistently southward after 06:45 UT, following a brief bi-polar oscillation. The IMF $B_{Y}$ component was positive throughout, except a brief negative excursion while the IMF was northward, and the IMF $B_{X}$ component changed from consistently negative to consistently positive around the interval of northward IMF. The solar wind speed $V_{S W}$ was close to $440 \mathrm{~km} \mathrm{~s}^{-1}$ for much of the period but rose to $480 \mathrm{~km} \mathrm{~s}^{-1}$ for a while after the period of northward IMF. The solar wind concentration $N_{S W}$ oscillated over the range 5-10 $\mathrm{cm}^{-3}$ until near 07:00 UT when it fell to a constant value near $2.5 \mathrm{~cm}^{-3}$.

\subsection{Polar cap and auroral electrojet response}

Figure 2 shows the ion temperature observed by the EISCAT VHF radar, operating in the CP-4-B experiment mode. In this mode, the radar observes simultaneously along two beam directions: beam 1 is at an azimuth $344^{\circ}$ east of geographic north and is perpendicular to the magnetic L-shells, 


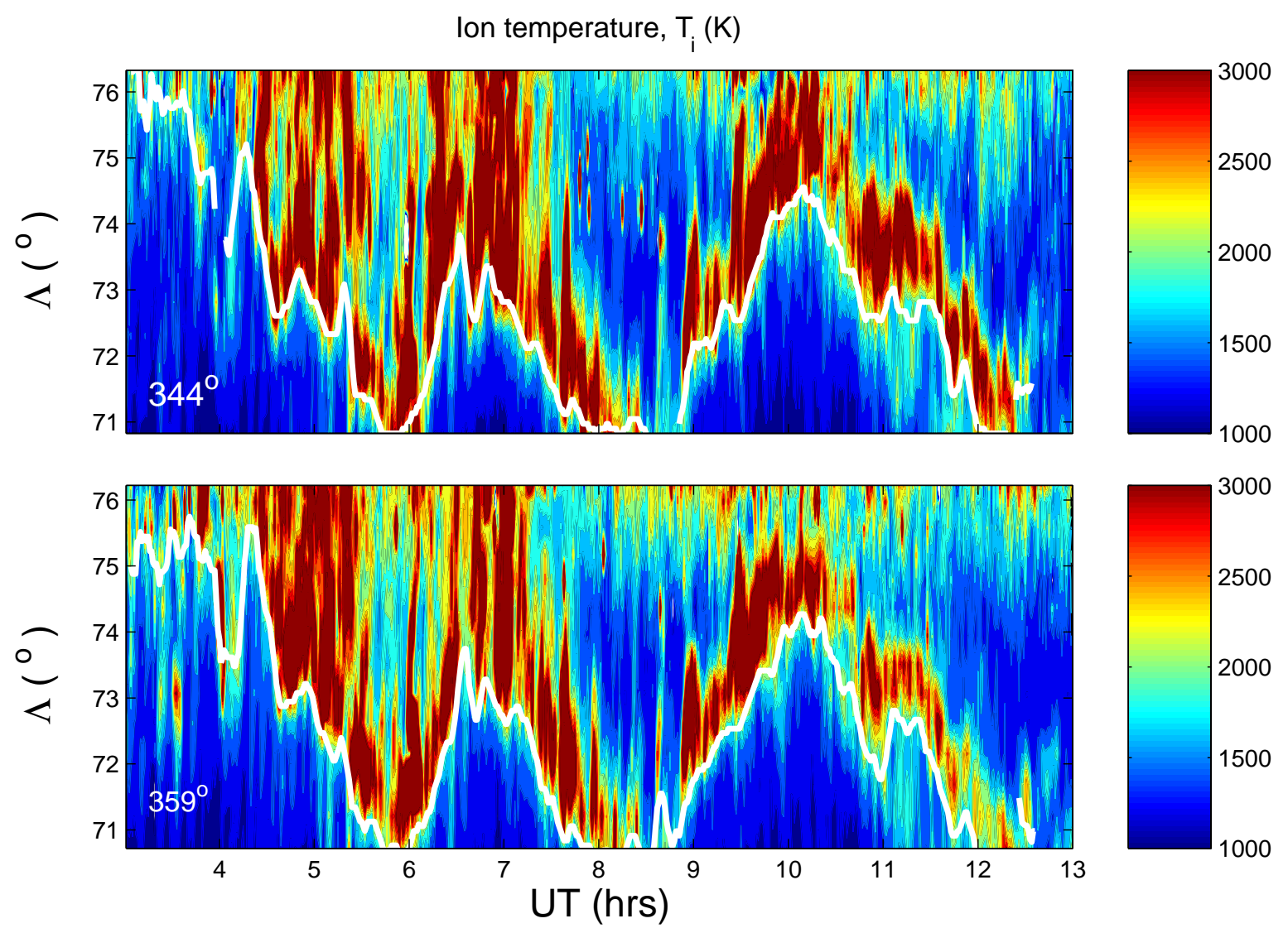

Fig. 2. One-min resolution observations on 23 November 1999 by the EISCAT VHF radar operating in the CP-4-B spilt-beam mode. Ion temperature, $T_{i}$, is colour contoured as a function of UT and invariant latitude, $\Lambda$, for (top) beam 1 (344 ${ }^{\circ}$ east of geographic north and perpendicular to the L-shells) and (bottom) for beam 2 (359 east of geographic north). The white lines in each case show 5-point running means of the invariant latitude where $T_{i}=2000 \mathrm{~K}$ on the equatorward edge of the high $T_{i}$ band.

beam 2 is at an azimuth $359^{\circ}$ east of geographic north. Both beams are at an elevation of $30^{\circ}$. Data are recorded every $10 \mathrm{~s}$, but all data used in the present paper have been postintegrated into 1-min periods to reduce observation errors. Radar range gates are $65 \mathrm{~km}$ in extent along the beam, covering approximately $50 \mathrm{~km}$ in the field-perpendicular plane $\left(\Delta \Lambda \approx 0.5^{\circ}\right)$. The invariant latitude $(\Lambda)$-MLT coordinates of the radar range gates depend on the beam direction, the range and the universal time (UT). At UT of thours, the magnetic local time (MLT) of all beam 1 gates is $(t+2.75) h$. For beam 2, the MLT is $(\mathrm{t}+3) \mathrm{h}$ at $\Lambda=70.8^{\circ}$, rising to $(\mathrm{t}+4) \mathrm{h}$ at $\Lambda=78.1^{\circ}$.

In Fig. 2, the observed ion temperature, $T_{i}$, is colour contoured as a function of UT and invariant latitude, $\Lambda$, for beam 1 (top) and for beam 2 (bottom). The white lines in both panels show the invariant latitudes of the $T_{i}=2000 \mathrm{~K}$ contours on the equatorward edge of the high $T_{i}$ band: in both cases, a 5-point running mean has been applied to the 1-min resolution EISCAT boundary data employed in this paper. This smoothes out faster fluctuations in the boundary location and also the quantum jumps in the latitudes caused by the range gating of the radar data. Both beams saw a band of high ion temperatures, which moved back and forth in latitude across the radar field-of-view (f-o-v). Similar bands have been seen moving poleward nearer dawn and dusk caused by polar cap contractions during substorm expansions (Lockwood et al., 1988; Fox et al., 1994), but such repetitive motions around noon have not been observed before. The gap in the high- $T_{i}$ band between 08:00 and 08:50 UT is attributed by Moen et al. (2004) to the effect of enhanced neutral winds driven by the persistent westward ion flow. This effect is discussed in greater detail in Paper II. The variations of other parameters observed by EISCAT have been presented by Moen et al. (2004).

Figure 3 analyses these boundary motions in the context of the observed variations in the IMF and the auroral electrojet. The top panel shows the IMF $B_{Z}$ component (in the GSM frame), as observed by Wind, lagged (by $-3 \mathrm{~min}$ ) to the predicted time of arrival at the dayside magnetopause. In all three panels of Fig. 3 (and in several of the subsequent figures), intervals of northward IMF are shaded grey. The middle panel shows the response of the auroral electrojet, quantified by the AL auroral electrojet index. Two substorms can be seen in the interval shown. During the first, AL fell to near $-400 \mathrm{nT}$ but this decrease ended at the same time as the abrupt northward turn of the IMF. During the second 


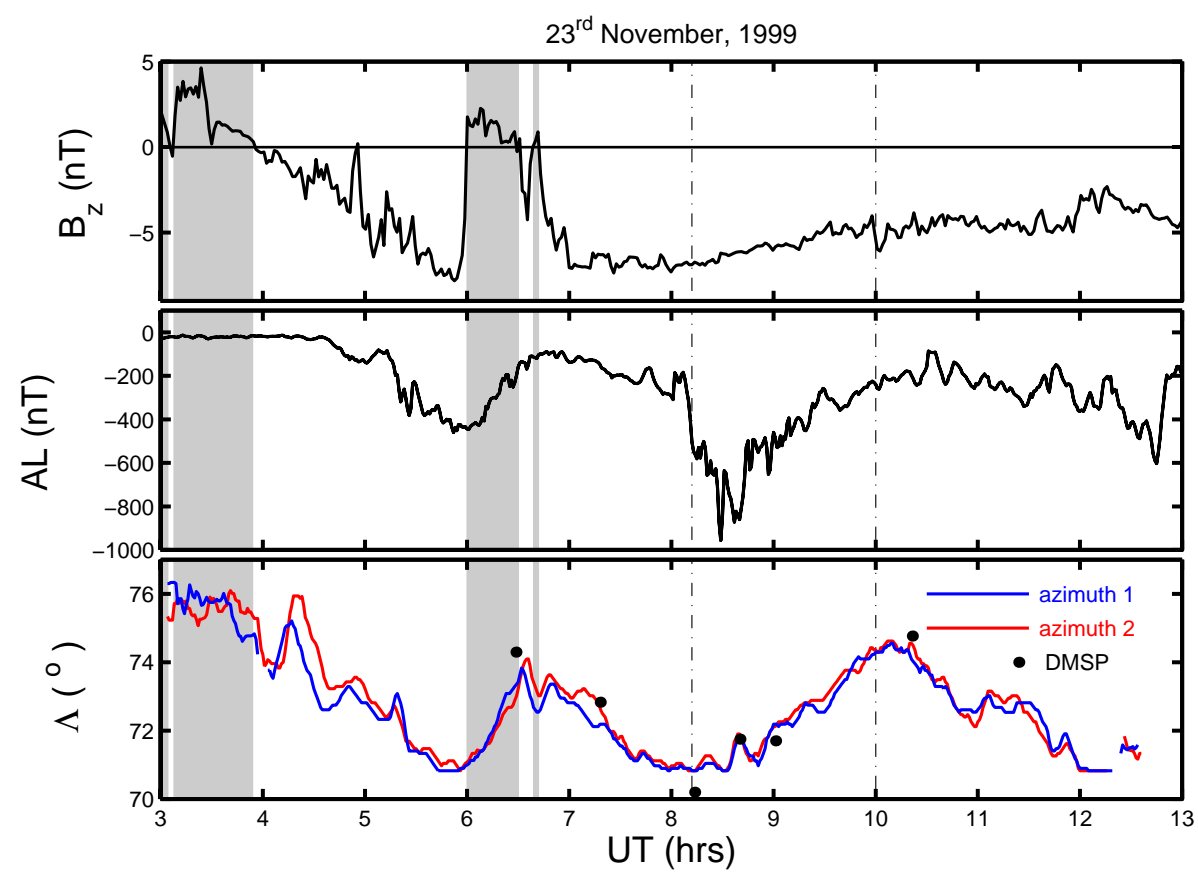

Fig. 3. (Top) The $B_{Z}$ component of the IMF in the GSM coordinate system, observed by the WIND spacecraft, lagged by the predicted propagation time from the satellite to the dayside magnetopause. (Middle) The auroral AL index. (Bottom) The latitude of the polar cap boundary determined from (in blue) beam 1 (azimuth $344^{\circ} \mathrm{E}$ of $\mathrm{N}$, along the geomagnetic meridian) and (in red) beam 2 (azimuth $359^{\circ} \mathrm{E}$ of $\mathrm{N}$, along the geographic meridian) of the EISCAT VHF radar operated in the CP-4-B mode (as shown in Fig. 2). The black points are the open closed boundary intersections seen by DMSP satellites at an MLT within $1.5 \mathrm{~h}$ of that of beam 1 of the EISCAT radar. The areas shaded grey are northward IMF and the vertical dot-dashed lines mark the expansion/recovery phases of the larger substorm.

substorm, AL fell to near $-900 \mathrm{nT}$ and the IMF remained negative at all times. The times of onset and full recovery for this second substorm are marked (in all three panels of Fig. 3 and in some subsequent figures) by vertical dot-dashed lines.

The bottom panel of Fig. 3 shows the invariant latitude of the equatorward edge of the persistent band of high ion temperatures, as shown by the white lines in Fig. 2. Moen et al. (2004) demonstrated that this boundary had a consistent, and relatively small, offset with respect to the inferred openclosed boundary (OCB). By comparing with particle data recorded during close conjunction passes by DMSP satellites, these authors found that the best estimates of the OCB latitude from the EISCAT data were made using the gradient of the electron temperature $\left(T_{e}\right)$ data (as used, for example, by McCrea et al., 2000) and that these were slightly equatorward of the equatorward edge of the band of very high ion temperatures. However, this $T_{e}$ boundary was not always detectable on this day, unlike that in $T_{i}$. It is noticeable that the enhanced $T_{e}$ values in the band are often smaller than the $T_{i}$ values: at such times the electron gas was being heated by the ion gas through the conduction term in the thermal balance equation and ion heating by enhanced flows is dominating over electron heating by sheath electron precipitation. In addition, in Paper II we discuss how there are also large fluctuations in $T_{e}$ associated with the plasma concentration variations caused by the passage of polar cap patches. These two factors often rendered the boundary much harder to define in
$\mathrm{T}_{e}$ than in $T_{i}$ on this day. Moen et al. (2004) demonstrated most of the high- $T_{i}$ band was caused by fast westward flow of newly-opened field lines under the magnetic curvature force, and thus was associated with the observed positive IMF $B_{Y}$ (e.g. Cowley et al., 1991a): only near dawn was the equatorward part of the high- $T_{i}$ band found to be on eastward (sunward) flow. The gap between the inferred OCB latitude (from the satellite data and the EISCAT $T_{e}$ measurements) is reduced to of order one radar range gate if a lower ion temperature threshold is used. We here adopted a value of $2000 \mathrm{~K}$, which is the lowest which consistently identifies the high$T_{i}$ band and which is sufficiently elevated above the inferred exospheric neutral temperature (approximately $1300 \mathrm{~K}$ ).

The solid points in the bottom panel of Fig. 3 show the OCB location found using DMSP satellite passes for which the boundary was intersected at an MLT that was within $1.5 \mathrm{~h}$ of beam 1 of the EISCAT radar. The identification of the OCB in the DMSP data is discussed in the following section. The comparison confirms that the $T_{i}=2000 \mathrm{~K}$ threshold is close to the OCB location.

The behaviour of the boundary latitude, as seen by both radar beams, is consistent with polar cap expansion and contraction during the substorm cycle. After the southward IMF turning near 04:00 UT, the boundary expanded equatorward, consistent with equatorward erosion by magnetopause reconnection and the production of newly-opened flux. This expansion continued when the first weak substorm commenced 

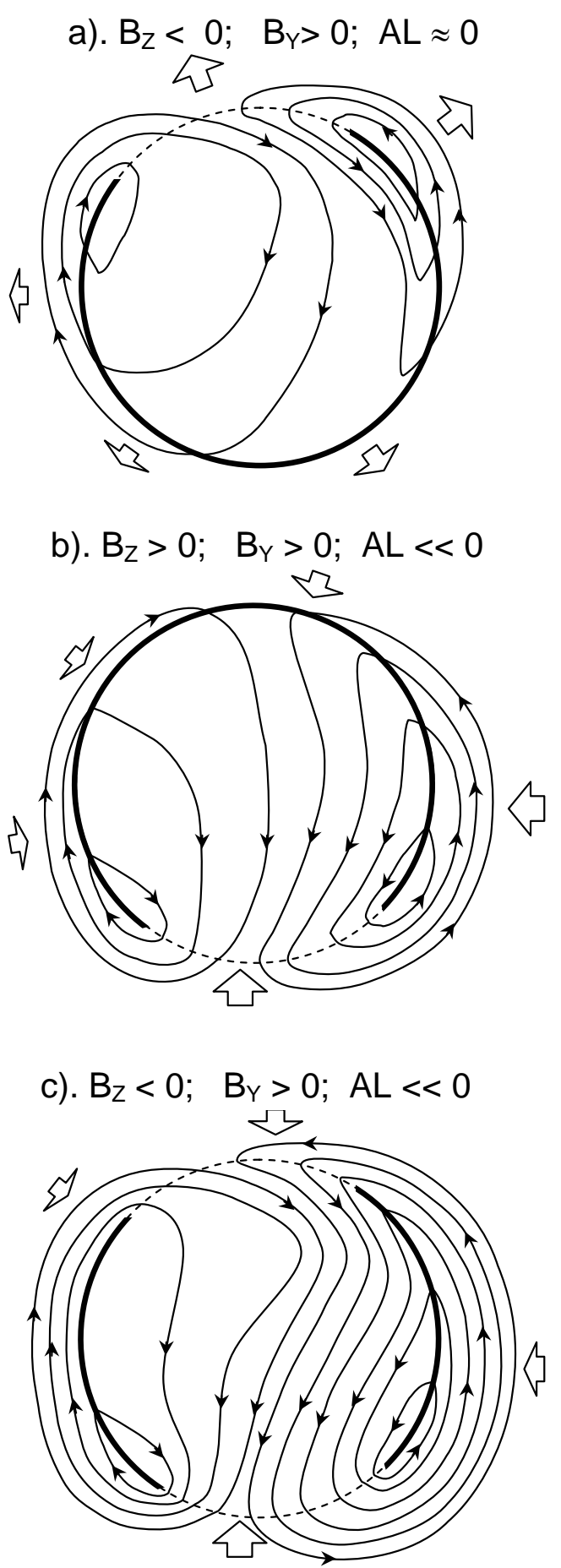

Fig. 4. Schematic of polar cap expansions and contractions. Lines with arrows are flow streamlines, thick solid lines are adiaroic (nonreconnecting) open closed field line boundary and dashed lines are footprints of the active dayside and nightside reconnection sites (in the magnetopause and cross-tail current sheet, respectively). Open arrows show the motion of the open-closed boundary. (a) Growth phase with IMF $B_{Z}<0, B_{Y}>0$, and $\mathrm{AL} \approx 0$. (b) Expansion-recovery phase with northward IMF: $B_{Z}>0, B_{Y}>0, \mathrm{AL} \ll 0$. (c) Expansionrecovery phase with southward IMF: $B_{Z}<0 ; B_{Y}>0$; $\mathrm{AL} \ll 0$. because the IMF became increasingly southward. When the IMF turned northward near 06:00 UT, the substorm activity peaked with AL near $-400 \mathrm{nT}$ and the boundary returned poleward. The brief bipolar oscillation in IMF $B_{z}$ was reflected in a brief equatorward and then poleward boundary motion, before a consistent equatorward erosion was reestablished under steady and strongly southward IMF. The equatorward erosion ended with the onset of the second, stronger substorm (AL falling to $-900 \mathrm{nT}$ ) and the boundary subsequently relaxed poleward throughout the expansion and recovery phase, despite the continuing southward IMF orientation. The poleward motion in this second substorm is slower than in the first, despite the lower $\mathrm{AL}$, presumably because the loss of open flux by tail reconnection was partially cancelled by ongoing open flux generation associated with the southward IMF. When AL returned to quiet values, the polar cap began to expand equatorward again. Figure 4 shows schematically the boundary motions and ionospheric convection predicted using the concepts of ionospheric flow excitation developed by Siscoe and Huang (1985), Lockwood et al. (1990) and Cowley and Lockwood (1992, 1997). The flow patterns are for the northern hemisphere and IMF $B_{Y}>0$, those being the conditions which apply during the interval discussed here, giving westward flow on newly-opened field lines in the northern hemisphere (Greenwald et al., 1990; Cowley et al., 1991a). Figure 4a applies to the growth phases, whereas Fig. $4 \mathrm{~b}$ is for the first substorm when the IMF has turned northward, and Fig. 4c applies to the second substorm expansion during which the IMF remains southward. Note that in parts a and b of Fig. 4, the dawn convection reversal boundary is shown as being slightly poleward of the OCB, as found during the northward-IMF dawn passes by DMSP satellites (for example, see Fig. 3 of Moen et al., 2004, Fig. 13 of the present paper, and Fig. 4b of Paper II) .

\subsection{DMSP particle observations}

We here make use of the electron and ion precipitation observed by DMSP satellites to identify the OCB and also whether or not reconnection is ongoing at that OCB. Figure 5 is an example where all features agree on the OCB location during an equatorward pass of DMSP F12. These features, observed around 14:11:05 UT (and near 11:00 MLT), are: 1.) a low latitude edge to sheath-like $(<1 \mathrm{keV})$ electron precipitation, seen in the electron spectrogram; 2.) a low latitude edge to sheath-like $(<3 \mathrm{keV})$ ion precipitation, seen in the ion spectrogram; and 3.) a high-latitude edge to magnetospheric $(>1 \mathrm{keV})$ electrons. In general, we find the third of these to be the least reliable of the indicators (see below). However, in this case, in addition to the dispersed appearance of the sheath ions in the cusp, the disappearance of the magnetospheric electrons was dispersed with the highest energy particles disappearing first (at the lowest latitude for these poleward-moving field lines and thus seen last by this equatorward-moving satellite). This electron dispersion reveals that reconnection was ongoing at the part of the OCB intersected. The ion dispersion in this 
F12

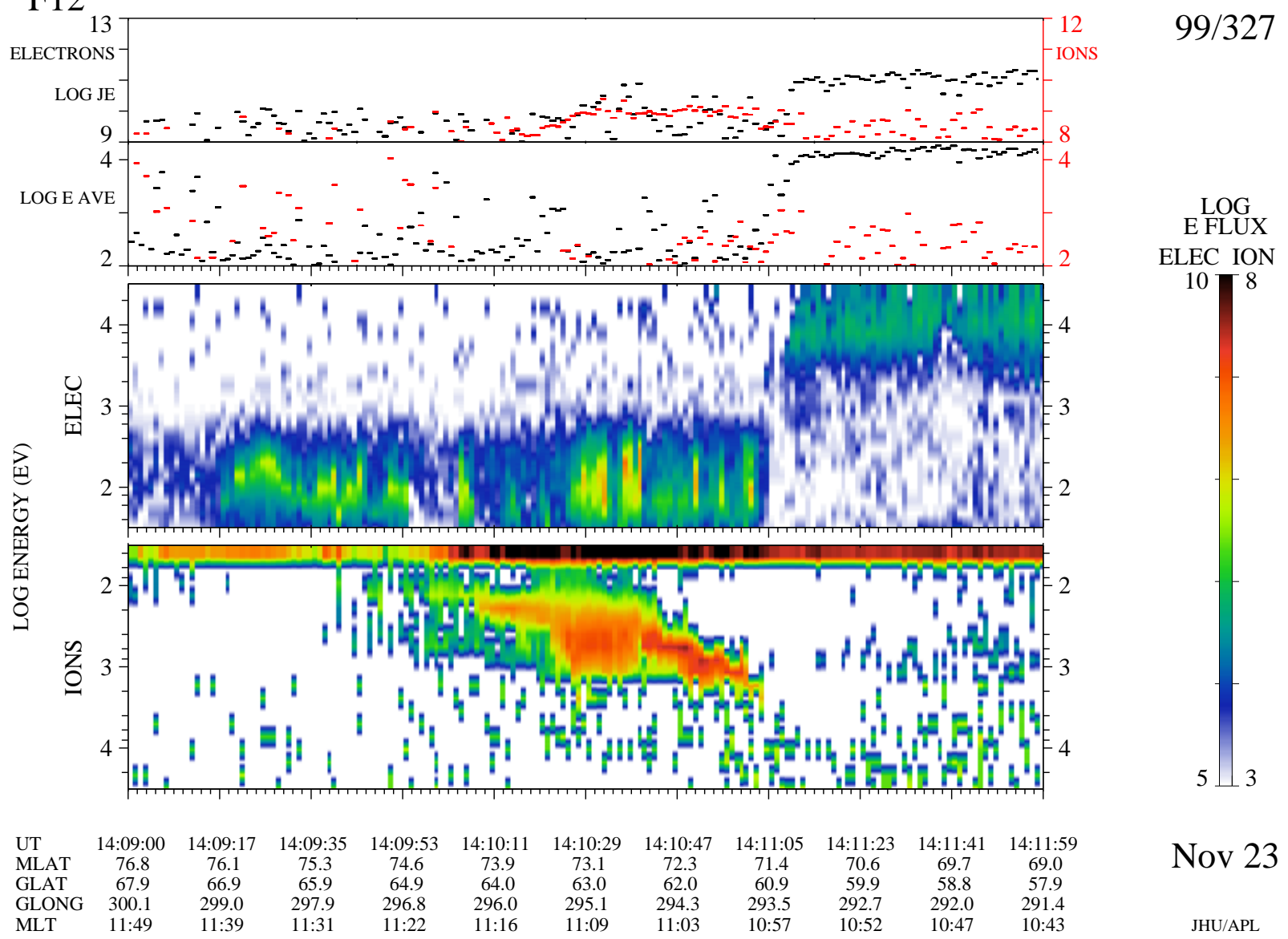

Fig. 5. Particle observations during a pass by the DMSP-F12 satellite through the open-closed field line boundary on 23 November 1999 . The top two panels give the integral energy flux and average energy of down-going electrons (in black) and ions (in red). The lower two panels show electron and ion spectrograms: the differential energy flux (in $\mathrm{cm}^{-2} \mathrm{~s}^{-1} \mathrm{sr}^{-1}$ ) is contoured on a log scale as a function of observation time and energy. Note that the energy scale is inverted (i.e. energy increases down the page) for the bottom panel (for ions). For each UT, the geomagnetic latitude (MLAT), geographic latitude (GLAT), geographic longitude (GLONG) and magnetic local time (MLT) of the spacecraft are given. This example shows a pass through an active reconnection X-line footprint in the pre-noon sector near 11:00 MLT (see text for details).

case extends to higher energies (giving differential energy fluxes exceeding $10^{7} \mathrm{~cm}^{-2} \mathrm{~s}^{-1} \mathrm{sr}^{-1}$ at energies above a $1 \mathrm{keV}$ threshold). The highest ion energies were observed on the most recently reconnected field lines (Lockwood, 1995) and will only be seen if the reconnection is ongoing at the MLT where the OCB is intersected. This is because the supply of the more energetic ions is quickly shut off as the field line evolves away from the reconnection site (Lockwood, 1997b). Observing (field-aligned) fluxes of sheath ions of energy exceeding $\mathrm{E}$ that are significantly greater than the noise level (we here adopt a threshold of $10^{7} \mathrm{~cm}^{-2} \mathrm{~s}^{-1} \mathrm{sr}^{-1}$ ) tells us that reconnection took place within the previous interval of $\delta \mathrm{t}=\mathrm{d}(\mathrm{m} / 2 \mathrm{E})^{1 / 2}$, where $\mathrm{m}$ is the ion mass and $\mathrm{d}$ is the field-aligned distance from the magnetopause $\mathrm{X}$-line to the ionosphere. For protons with $\mathrm{E} \geq 1 \mathrm{keV}$ and a typical $\mathrm{d}$ of $20 R_{E}, \delta \mathrm{t} \leq 5 \mathrm{~min}$ and for a typical convection speed of $V=1 \mathrm{kms}^{-1}$, this places the satellite within about $300 \mathrm{~km}$ of the reconnection site. One last feature to note is that the dispersion curve seen in the lowest energy sheath ions (the low-energy time-of-flight ion "cut-off") is not smooth but shows small fluctuations. Such features are often accompanied by poleward-moving ionospheric events, in which case they are caused by small, short-period reconnection rate variations (Cowley et al., 1991b, Lockwood and Smith, 1992; Newell and Meng, 1991; Escoubet et al., 1992; Lockwood et al., 1993a, Lockwood and Davis, 1995; 1996; Pinnock et al., 1995; Farrugia et al., 1998; Morley and Lockwood, 2003; Oksavik et al., 2004). Cusp ion steps originating from purely spatial variations in reconnection rate are not accompanied by poleward-moving events (Lockwood, 1996). Paper II discusses poleward-moving events seen by EISCAT in close conjunction to the cusp ion steps discussed here and we conclude that they therefore reveal temporal variations in reconnection rate.

Figure 6 presents a second example of ongoing, pulsed reconnection (by the above criteria) taking place at the OCB observed by the DMSP F14 satellite at 08:40:15 UT and 12:30 MLT. In this case, the sheath particle precipitation 
F14
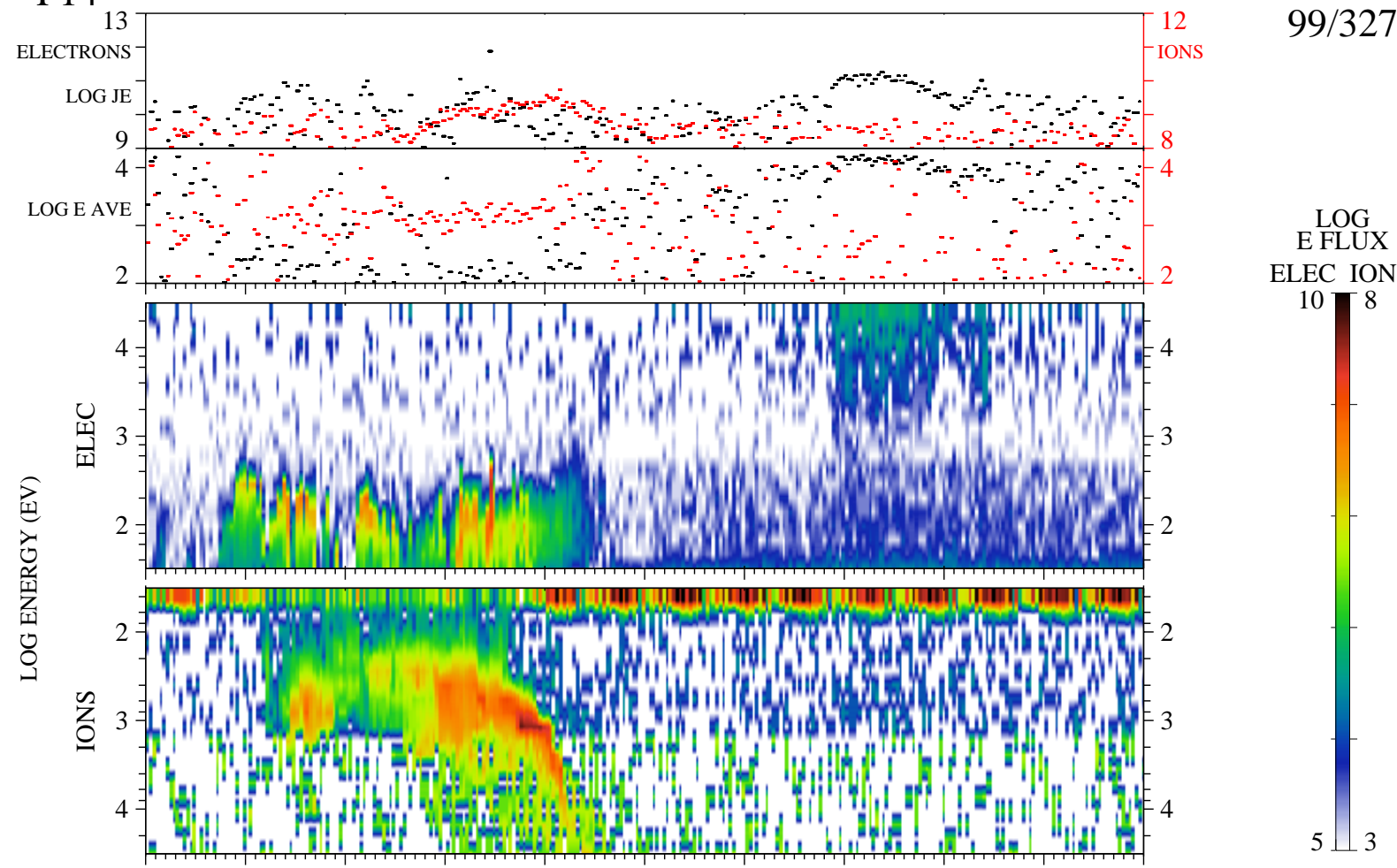

\begin{tabular}{|c|c|c|c|c|c|c|c|c|c|c|c|}
\hline UT & 08:38:00 & 08:38:29 & 08:38:59 & 08:39:29 & 08:39:59 & 08:40:29 & 08:40:59 & $08: 41: 29$ & $08: 41: 59$ & $08: 42: 29$ & $08: 42: 59$ \\
\hline MLAT & 74.8 & 74.3 & 73.6 & 72.8 & 71.7 & 70.7 & 69.5 & 68.1 & 66.8 & 65.4 & 63.8 \\
\hline SLAT & 79.8 & 78.8 & 77.6 & 76.4 & 74.9 & 73.5 & 72.1 & 70.4 & 68.9 & 67.3 & 65.6 \\
\hline GLONG & 62.0 & 54.2 & 47.2 & 41.9 & 37.1 & 33.5 & 30.4 & 27.4 & 25.1 & 23.1 & 21.2 \\
\hline MLT & $14: 08$ & $13: 43$ & $13: 18$ & $12: 57$ & $12: 36$ & $12: 20$ & $12: 05$ & $11: 49$ & $11: 37$ & $11: 27$ & $11: 16$ \\
\hline
\end{tabular}

Fig. 6. Same as Fig. 5, showing a noon pass of DMSP-F14 through the footprint of an active reconnection site near 12:30 MLT.

edges agree, but sufficient fluxes of magnetospheric electrons were absent in the outer closed field line region and thus only the slightest hint of a magnetospheric electron edge can been seen at the OCB inferred from the sheath particles. Because there were magnetospheric electrons at lower latitudes, an edge is seen $3^{\circ}$ of invariant latitude equatorward: however, close inspection reveals that the highest energies disappear last (as the field lines propagate poleward) and thus this is not an OCB signature but is caused by the past history of energetic magnetospheric electron injection by substorms. We conclude that the high-latitude edge of magnetospheric electrons is not always a reliable OCB indicator. As in the previous example, ion fluxes exceeding $10^{7} \mathrm{~cm}^{-2} \mathrm{~s}^{-1} \mathrm{sr}^{-1}$ extend to energies above a $1 \mathrm{keV}$ threshold and there are small cusp ion steps in the low-energy cut-off dispersion, We again interpret these facts as showing, respectively, that reconnection was taking place locally at the observed OCB and that the local reconnection rate was pulsed, with short intervals of lower or zero reconnection rate.

Figure 7 is an example of a pass from closed to open field lines by DMSP F13 where no sheath plasma is observed. The best estimate of the OCB intersection is at 09:47:35 (near 15:50 MLT). In this case, a strong inverted- $\mathrm{V}$ electron precipitation feature was seen up to the poleward edge of the magnetospheric electron precipitation, poleward of which the precipitation is typical of the polar cap. Such a boundary is here taken to be a signature of a non-reconnecting OCB as the satellite moves from closed field lines onto field lines that have been open for a sufficiently long interval for all cusp/mantle precipitation to have ceased. The broad band of inverted-V precipitation is consistent with region-1 upward currents just equatorward of the OCB.

The last example presented here (Fig. 8) is an OCB intersection made by DMSP F13 at 09:55:54 UT (09:20 MLT). In this case, there is some suggestion of a high-latitude edge of magnetospheric electrons, but this boundary is not well defined. Two brief bursts of sheath electrons were seen, bounding a region of almost undispersed ion precipitation. We interpret this as a cusp pass where flow streamlines were close to perpendicular to the satellite path. This is consistent with the flow schematics sketched for this interval in Fig. 4 and by Moen et al. (2004). At the equatorward edge of the sheath ion precipitation, no significant fluxes were observed above $1 \mathrm{keV}$ and thus, although the field lines observed were opened sufficiently recently for sheath ions to be present, the most recently-opened field lines were not observed and we infer that the OCB intersected was not reconnecting locally (from the discussion above, within about $300 \mathrm{~km}$ ). 
F13

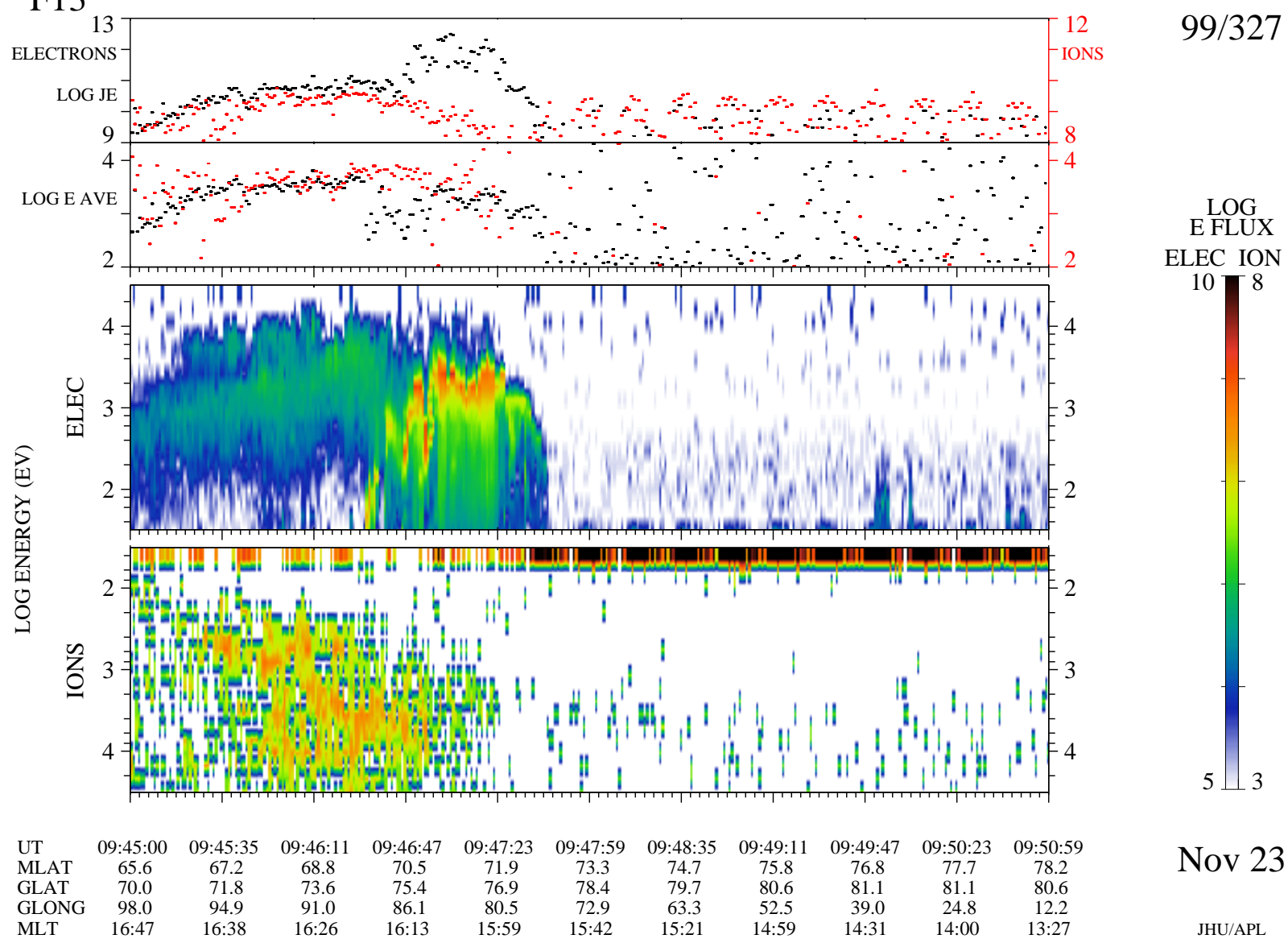

Fig. 7. Same as Fig. 5, showing a dusk pass of DMSP-F13 through the footprint of an adiaroic (non-reconnecting) open-closed boundary near 16:00 MLT. Note that no sheath-like precipitation was observed.

All the dayside passes by DMSP satellites on 23 November fell into one of the classes defined by the examples presented in this section. Thus in each case, an OCB location was defined and, using the $1-\mathrm{keV}$ threshold for any sheath ion fluxes as discussed above, we classified the boundary as either "reconnecting" or "adiaroic" (non-reconnecting). Figure 9 shows the dayside OCB crossings between 00:00 and 16:00 UT on an invariant latitude - MLT plot. The red triangles and black squares are for, respectively, reconnecting and adiaroic OCB classifications. It can be seen that the reconnection was consistently seen between about 09:00 and 15:30 MLT: there is some indication of small merging gap extent variations, but this appears to have been a relatively stable reconnection region over the entire interval. The OCB crossings to the dusk side of the merging gap were consistently of the form shown in Fig. 7, whereas those to the dawn side were like that shown in Fig. 8. This is consistent with the sheath plasma cusp/mantle plume being angled toward dawn by the strong positive IMF $B_{Y}$ component (Cowley et al., 1991a). The inverted-V events, seen in the electron data from the dusk sector (Fig. 7) are consistent with the region-1 upward currents, equatorward of the OCB.
Figure 10 analyses the latitudinal variation of these inferred OCB locations. The OCB intersections are divided into three local time sectors, MLT $\leq 10 \mathrm{~h}$ (red squares), $10<$ MLT $\leq 14 \mathrm{~h}$ (blue circles), and MLT $>14 \mathrm{~h}$ (black triangles). From Fig. 9, all observations in the middle category relate to reconnecting OCB segments. To some extent, the behaviour observed by EISCAT (Fig. 3, bottom panel) is seen in all three MLT sectors, with equatorward erosion when the IMF is southward, interrupted by the two substorm expansion/recovery phases when the boundary returns poleward. The motions are largest in amplitude in the dusk sector, and similar for the noon and dawn sectors. This clearly demonstrates that the equatorward and poleward motions seen by EISCAT do indeed reflect motions of the open closed boundary throughout the dayside.

\subsection{EISCAT velocity data}

The top panel of Figure 11 shows the orientation of the $T_{i}=2000 \mathrm{~K}$ contour, deduced from the points where it intersects the two beams of the EISCAT CP-4-B experiment. The angle $\delta$ is presented, which is the angle that the contour (and the OCB that is thought to be close to and parallel to this 
F13

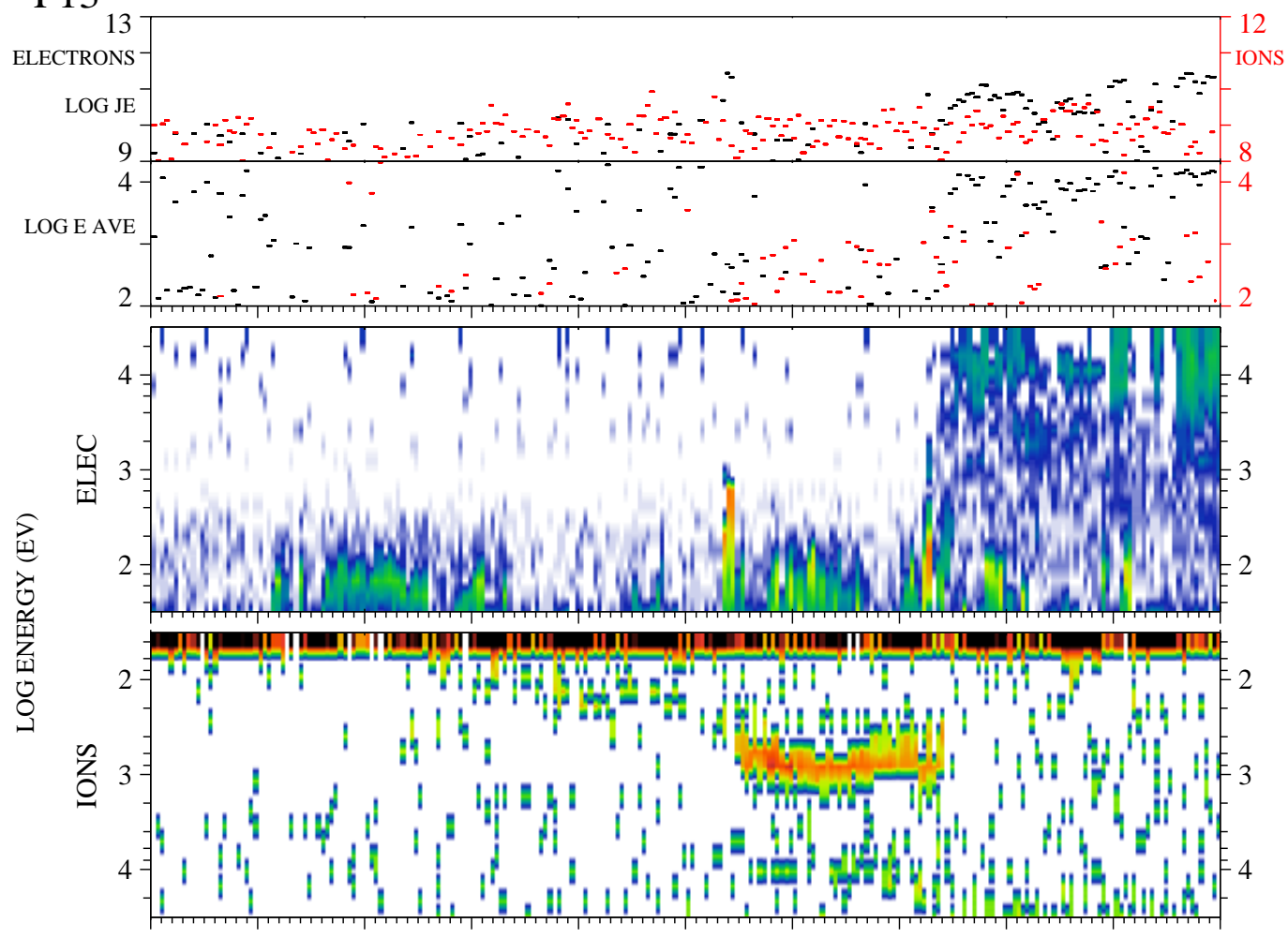

$99 / 327$

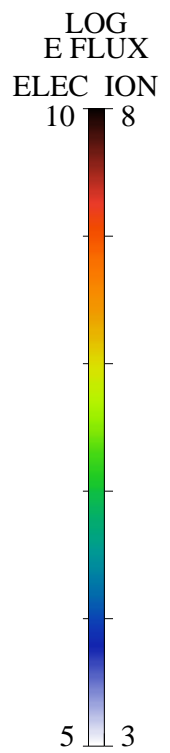

\begin{tabular}{|c|c|c|c|c|c|c|c|c|c|c|c|}
\hline UT & 09:53:00 & $09: 53: 23$ & $09: 53: 47$ & $09: 54: 11$ & $09: 54: 35$ & 09:54:59 & $09: 55: 23$ & $09: 55: 47$ & 09:56:11 & $09: 56: 35$ & $09: 56: 59$ \\
\hline MLAT & 78.0 & 77.6 & 77.1 & 76.5 & 75.8 & 75.0 & 74.2 & 73.2 & 72.3 & 71.2 & 70.2 \\
\hline GLAT & 76.4 & 75.4 & 74.2 & 73.1 & 71.8 & 70.6 & 69.4 & 68.1 & 66.8 & 65.4 & 64.1 \\
\hline GLONG & 341.6 & 337.9 & 334.6 & 331.8 & 329.3 & 327.1 & 325.2 & 323.4 & 321.9 & 320.3 & 319.0 \\
\hline MLT & $11: 24$ & $11: 02$ & $10: 41$ & $10: 23$ & $10: 06$ & 09:50 & 09:37 & $09: 24$ & $09: 13$ & 09:02 & 08:53 \\
\hline
\end{tabular}

Nov 23

JHU/APL

Fig. 8. Same as Fig. 5, showing a dawn pass of DMSP-F13 through the footprint of an adiaroic (non-reconnecting) open-closed boundary near 09:00 MLT. Note that sheath-like precipitation was observed, but ion energies near the open-closed boundary did not exceed 1 keV.

contour) made with the magnetic L-shells (a positive $\delta$ being defined as the OCB being oriented north-east to south-west with respect to the $\mathrm{L}$-shell). In general, the inferred OCB was close to L-shell aligned, but perturbations between $-20^{\circ}$ and $+30^{\circ}$ were observed. The angle $\delta$ is computed using the 5point running means of boundary latitudes shown in Figs. 2 and 3. During periods of southward IMF $\delta$ was generally positive, at least up until about 10:00 UT. For this morning sector data this corresponds to the boundary being further poleward near noon, which is consistent with the expected orientation of the auroral oval. During 10:00-11:00 UT the boundary is very close to L-shell-aligned, and after 11:00 UT there was a growing tendency for negative $\delta$, consistent with the expected orientation of the auroral oval for the afternoon sector. There are several major perturbations to this trend, including two large negative excursions in $\delta$ that occur in the morning sector when the IMF turns northward.

The lower two panels of Fig. 11 show the line-of-sight velocities ( $V_{1}$ and $V_{2}$, defined as positive away from the radar) observed along beams 1 and 2 for the range gate closest to, yet poleward of, the $T_{i}=2000 \mathrm{~K}$ contour. As for the boundary latitudes and orientation, a 5-point running mean has been applied to the 1-minute resolution $V_{1}$ and $V_{2}$ data. These two velocities are combined in order to generate components of the plasma flow using the beam-swinging technique, as modified by Fox et al. (2001). Essentially, it is assumed that the flow is constant between the two beams along lines parallel to the OCB (as opposed to along L-shells which is the assumption that has often been made in the past). Four components of field-perpendicular convection are derived, $V_{N}, V_{W}$ and $V_{\perp N}$ and $V_{\| W}: V_{N}$ and $V_{W}$ are the northward and westward components in geomagnetic coordinates (i.e., respectively perpendicular to and parallel to the L-shells); $V_{\perp N}$ is the northward component perpendicular to the OCB boundary, i.e. in a direction that makes an angle $(\delta+\pi / 2)$ with respect to the L-shells, and $V_{\| W}$ is the westward flow parallel to the OCB. Because beam 1 points normal to the L-shells $V_{1}=V_{N} \cos (\varepsilon)+\mathrm{V}_{||} \sin (\varepsilon)$, where $V_{\|}$is the field parallel velocity and $\varepsilon$ is the elevation angle between the beam and the plane normal to the field lines: the second term can be neglected because both $V_{\|}$and $\varepsilon$ are small, and thus $V_{1} \approx \mathrm{V}_{N}$ $\cos (\varepsilon)$. There are, of course, errors introduced into the vector flow data by the beamswinging assumption (Freeman et al., 1991): however, in this paper we are mainly concerned with the component of flow across the $\mathrm{OCB}, V_{\perp N}$, which is very close to $V_{N}$ because the angle $\delta$ is small. The component $V_{N}$ 


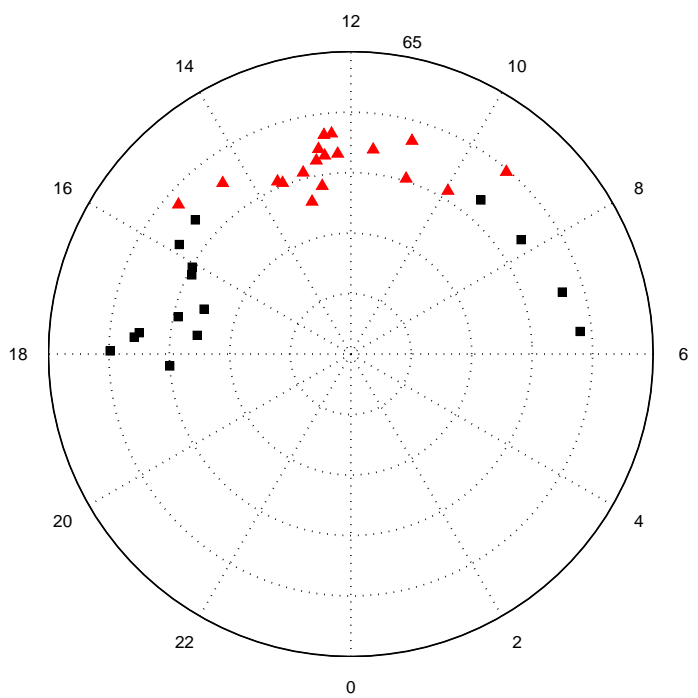

Fig. 9. MLT-invariant latitude $(\Lambda)$ plot of the locations of all of the open-closed boundary crossings observed by the DMSP satellites between 03:00 and 13:00 UT on 23 November 1999. 12:00 MLT is at the top of the plot and concentric circles are for $\Lambda$ of $65(5) 85^{\circ}$. The red triangles are for active reconnection footprints (identified by sheath electron and ion precipitations with ion energies near the boundary exceeding $1 \mathrm{keV}$ ). Black squares are for non-reconnecting (adiaroic) open-closed boundary crossings.

is very accurately measured because it is so closely related to $V_{1}$ and thus beamswinging errors are not a major concern. Note however, that the $V_{\perp N}$ variation shown in Fig. 12 is nevertheless different to that in $V_{1}$ (middle panel Fig. 11), the difference being the effect of the variations in the OCB orientation $\delta$.

An analysis of the errors in the radar line-of-sight velocity determination was made by Williams et al. (1996). These authors exploited a previous version of the radar mode used here (CP-4-A), in which the same radar pulse modulation was transmitted on several adjacent frequencies simultaneously: by taking the standard deviation of the 1-o-s velocity measured at different frequencies, the measurement uncertainty was quantified. The error depends on the signal-tonoise ratio of the data, as expected, and for the values observed on the day studied here, the estimated uncertainties are everywhere smaller than $\pm 100 \mathrm{~ms}^{-1}$, which we here take to be the error in $V_{N}, \varepsilon_{V N}$. Usually, the angle $\delta$ is near zero so $V_{N} \approx V_{\perp N}$; however, the effect of non-zero $\delta$ depends on the prevailing flow along the L-shells. Because of the dependence on the observed $V_{W}$ and $\delta$, the uncertainty for each $V_{\perp N}$ value has to be evaluated separately, using $\varepsilon_{V N}$ and an uncertainty in $\delta$ which corresponds to one range gate across the separation of the two beams at the $\Lambda$ in question. For the interval studied, $97 \%$ (the $2 \sigma$ level) of the error values obtained, $\varepsilon_{V \perp N}$, were smaller than $140 \mathrm{~ms}^{-1}$.

Because we are most interested in the poleward flow across the boundary, which is largely determined by $V_{1}$, we here ascribe the velocity measurements to the MLT of beam 1 (i.e., at UT of $\mathrm{th}$, the MLT is $\mathrm{t}+2.75 \mathrm{~h}$ ).

Figure 12 shows (in black) the $V_{\perp N}$ derived from the 5point running means of $V_{1}, V_{2}$ and $\delta$. The mauve line shows the boundary velocity $V_{B}$ in the same direction (i.e. northward, normal to the boundary) derived for the $T_{i}=2000 \mathrm{~K}$ contour motion shown in Figs. 2 and 3c. It can be seen that for most of the time before 06:45 UT, there is considerable agreement between the two, despite great variability in both. The uncertainty in the boundary velocity corresponds to one range gate $(50 \mathrm{~km})$ over the 5-min smoothing timescale used, giving $\varepsilon_{V B} \approx 170 \mathrm{~ms}^{-1}$. After 06:45 UT, $V_{\perp N}$ was consistently greater than $V_{B}$. When $V_{\perp N}=\mathrm{V}_{B}$, the plasma and frozen-in field were moving with the boundary, but not across it: the boundary segment was "adiaroic" and no reconnection was taking place at the MLT observed. When $V_{\perp N}>V_{B}$, the plasma and field were flowing poleward into the boundary, the effect of magnetopause reconnection generating new open flux. Thus EISCAT did not see much reconnection until 06:45 UT, after which it consistently observed ongoing reconnection. This was the UT at which the radar field of view moved to about 09:30 MLT, which was near the end of the reconnection merging gap deduced from the ensemble of DMSP satellite passes in Fig. 9. Thus the EISCAT observation were consistent with the DMSP data and a relatively stable reconnection X-line and merging gap between 09:00 and 15:30 MLT.

The magnetopause reconnection rate, $\mathrm{E}$, is related to the ionospheric velocity difference $V^{\prime}=\left\{\mathrm{V}_{\perp N}-\mathrm{V}_{B}\right\}$ by:

$E=\left|\underline{V^{\prime}} \times \underline{B}_{i}\right| / L_{X}=\left(V_{\perp N}-V_{B}\right) B_{i} / L_{X}$,

where a length $\mathrm{L}_{X}$ along the reconnection $X$-line maps magnetically to unit length along the ionospheric merging gap. Figure 13 shows the variation in $V^{\prime}$ (in blue) and the variation of the westward, along-OCB component $V_{\| W}$ (in red). The uncertainty in $V^{\prime}$ is $\varepsilon_{V^{\prime}}=\left\{\varepsilon_{V \perp N}^{2}+\varepsilon_{V B}^{2}\right\}^{1 / 2}$ and using the estimates for $\varepsilon_{V \perp N}$ and $\varepsilon_{V B}$ quoted above, we obtain an uncertainty $\varepsilon_{V^{\prime}}=220 \mathrm{~ms}^{-1}$. Note that before 06:45 UT, the fluctuation level in both $V_{\perp N}$ and $V_{B}$ greatly exceeds $\varepsilon_{V^{\prime}}$ (Fig. 12) but the difference $V^{\prime}$ (Fig. 13) rarely exceeds this uncertainty. Thus although there are rapid variations in the boundary location at this time, there are few significant differences between the boundary and plasma flow and no flow across the boundary in its own rest frame (reconnection) is detected.

The values of $V^{\prime}$ were generally low before 06:45 UT, although there were brief periods when they exceeded zero by more than the above uncertainty estimate $\left(\varepsilon_{V^{\prime}}=220 \mathrm{~ms}^{-1}\right)$, which could be caused by brief expansions of the active merging gap over the MLT of EISCAT. However, there were also negative values of $V^{\prime}$. These could be caused by field line closure by reconnection at the sunward edge of both tail lobes with a northward-pointing IMF, as discussed by Song and Russell (1992) and as simulated using a global MHD model by Richard et al. (1994). Such dayside closure of open flux has been inferred from the cusp aurora by Lockwood and Moen (1999) and from magnetopause electron flows by Onsager et al. (2001). Although sunward convection in both 


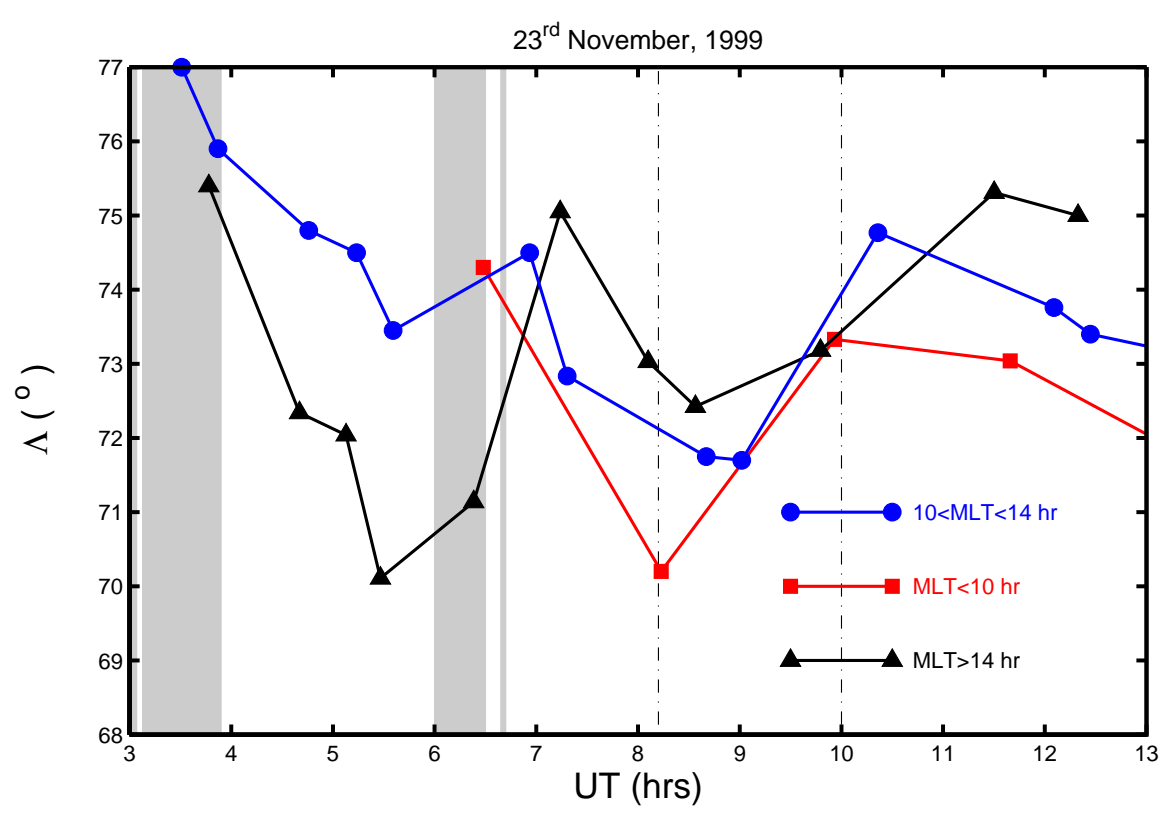

Fig. 10. Invariant latitudes $\Lambda$ of DMSP satellite crossings of the open-closed boundary in the $10<\mathrm{MLT} \leq 14 \mathrm{~h}$ sector (blue circles), at MLT $\leq 10 \mathrm{~h}$ (red squares); and MLT $>14 \mathrm{~h}$ (black triangles). As in Fig. 3, the areas shaded grey are northward IMF and the vertical dotdashed lines mark the expansion/recovery phases of the larger substorm.

polar caps, expected for this dayside closure of open flux, is sometimes observed (Reiff, 1982), a more normal behaviour is sunward flow in just one (the summer) polar cap (Crooker and Rich, 1993): this would cause "stirring" of the open flux poleward of the OCB, but not negative $V^{\prime}$ (Lockwood, 1998; Lockwood and Moen, 1999). We note, using the grey bands in Fig. 13, that there is no clear relationship of $V^{\prime}<0$ with northward IMF. Therefore it seems more likely that these events demonstrate the experimental uncertainties in the $V^{\prime}$ estimates and only a very few data points are negative by more than the estimated uncertainty $\varepsilon_{V^{\prime}}$ (i.e., $V^{\prime}<220 \mathrm{~ms}^{-1}$ ).

After the return to southward IMF at 06:45 UT, EISCAT was at an MLT large enough to see consistent reconnection signatures $\left(V^{\prime}>0\right)$. After 06:45 UT, $V^{\prime}$ usually exceeded the uncertainty $\varepsilon_{V^{\prime}}$, although there were brief intervals when no reconnection could be detected. EISCAT saw this reconnection over roughly the same MLT range as the DMSP satellites (9:00-15:30 MLT): this is consistent with the broad inflow region into the polar cap (e.g. Jørgensen et al., 1984) as opposed to a narrow convection "throat" (e.g. Heelis et al., 1976). The reconnection rate appears pulsed with several clear peaks in $V^{\prime}$ on 10-min timescales, as well as smaller variations on shorter timescales. Some of these peaks may be caused by the uncertainties in $V^{\prime}$ discussed above but most exceed $500 \mathrm{~ms}^{-1}$ and so cannot be explained by the uncertainty $\varepsilon_{V^{\prime}}$. The periodicity is consistent with the distributions of repeat periods of signatures attributed to reconnection pulses at the magnetopause and in the ionosphere (respectively, Lockwood and Wild, 1993; McWilliams et al., 2000). Interestingly, the variations in $V^{\prime}$ matched closely those in $V_{\| W}$, showing that the reconnection rate pulses also caused increases in the convection velocity along the boundary (and these tend to persist after $V^{\prime}$ has decayed again). Such a behaviour has been seen over extensive regions of the dayside by Moen et al. $(1995,1996)$. The bursts in $V_{\| W}$ were first reported by Lockwood et al. (1989a, b) and confirmed to be longitudinally extensive flow channels by Pinnock et al. (1993). Before 07:45 UT, the westward flow along the poleward side of the OCB, $V_{\| W}$, is generally negative, consistent with the eastward flow found in a narrow band poleward of the OCB by the DMSP satellites (see Moen et al. 2004, Fig. 3). Thus the sunward flow in the LLBL reported by Moen et al. (2004) is a persistent feature in these data, and was previously reported by Nishida et al. (1993) and Fujimoto et al. (1998). After 07:45 UT the flow along the poleward side of the boundary is westward, again consistent with the DMSP passes (Moen et al., 2004, Fig. 5).

\section{Conclusions}

We have inferred motions of the dayside open-closed field line boundary (OCB) from an unusually persistent band of high ion temperatures $\left(T_{i}\right)$ that was observed by the EISCAT VHF radar on 23 November 1999. As an indicator of the OCB location that was both reliable and persistent on this day, we have employed the equatorward edge of the observed fast westward flow, which is on newly-opened field lines and caused by the curvature force arising from reconnection with an interplanetary magnetic field with a large positive $B_{Y}$ component. We use the $T_{i}=2000 \mathrm{~K}$ contour as a proxy for the OCB and good agreement is found with the OCB locations deduced using particle observations from close conjunctions of DMSP satellites. 


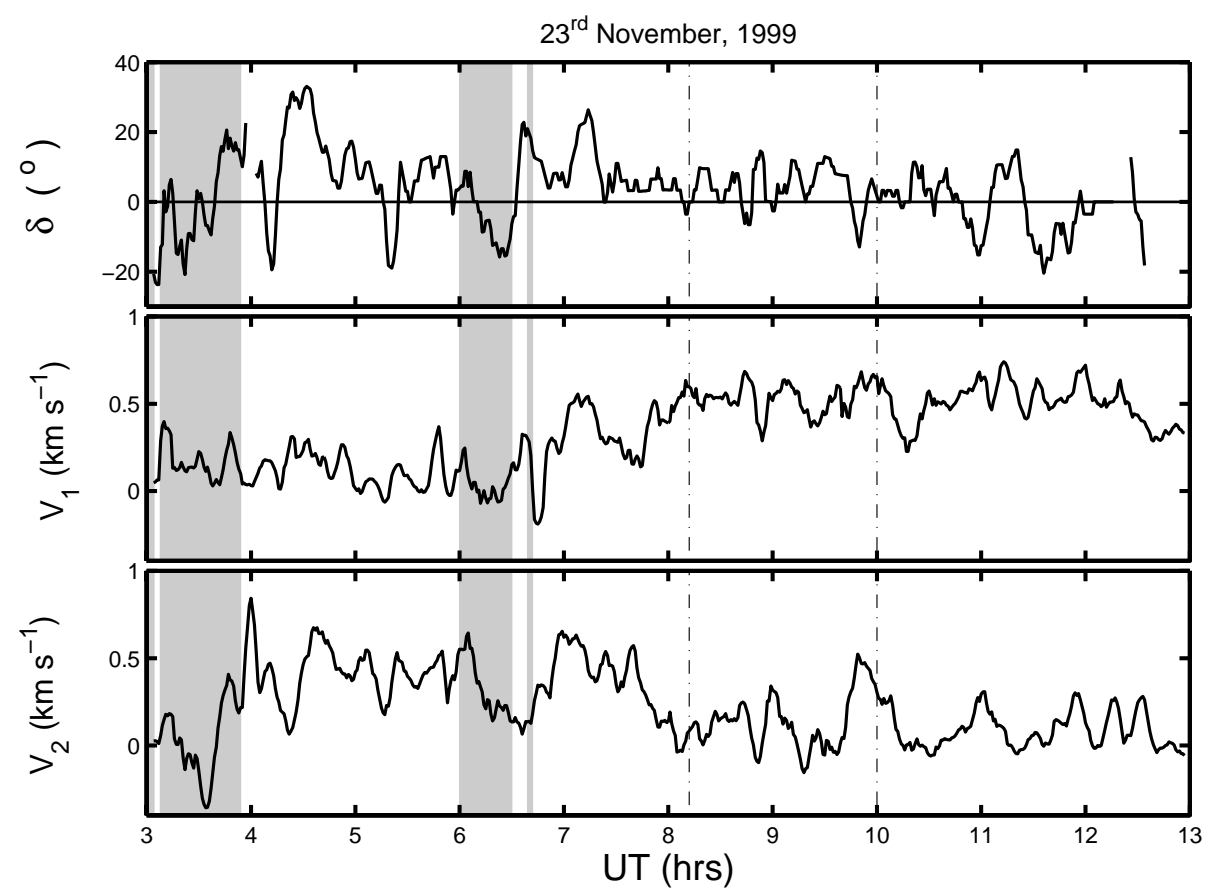

Fig. 11. (Top) Variations of the angle between the polar cap boundary and L-shells ( $\delta$ - positive values denoting a north-east to south-west orientation of the boundary). (Middle and Bottom) the line-of-sight velocities observed along beam 1 and beam $2\left(\mathrm{~V}_{1}\right.$ and $V_{2}$, respectively) for the range gates immediately poleward of the open-closed boundary signature. Data are 5-point running means of 1-min data. As in Fig. 3, areas shaded grey are northward IMF and the vertical dot-dashed lines mark the expansion/recovery phases of the larger substorm.

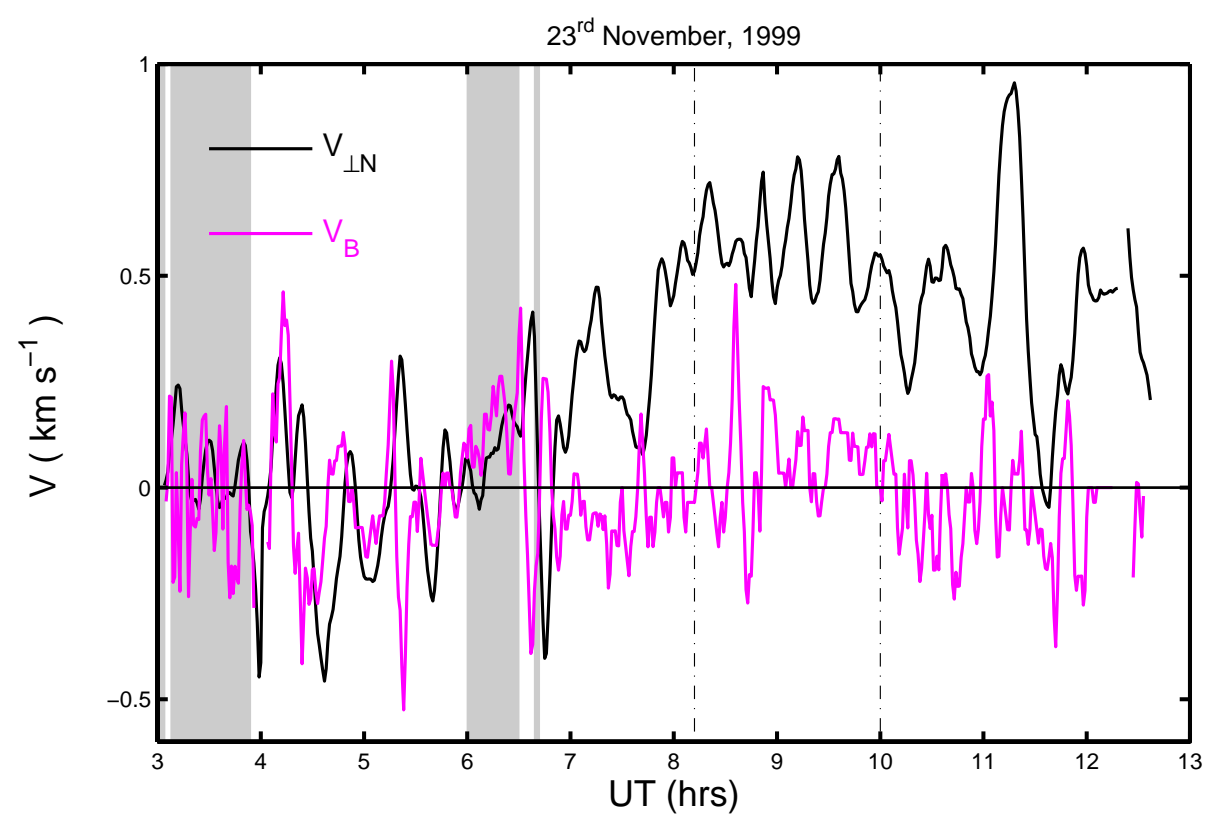

Fig. 12. (Black) Variations of the boundary normal convection velocity $V_{\perp N}$ derived by combining $V_{1}$ and $V_{2}$ for the range gates immediately poleward of the open-closed boundary signature. (Mauve) the velocity of the boundary motion $V_{B}$. Both velocities are in the field-perpendicular direction and both are positive poleward. Data are 5-point running means of 1-min data. As in Fig. 3, areas shaded grey are northward IMF and the vertical dot-dashed lines mark the expansion/recovery phases of the larger substorm. 


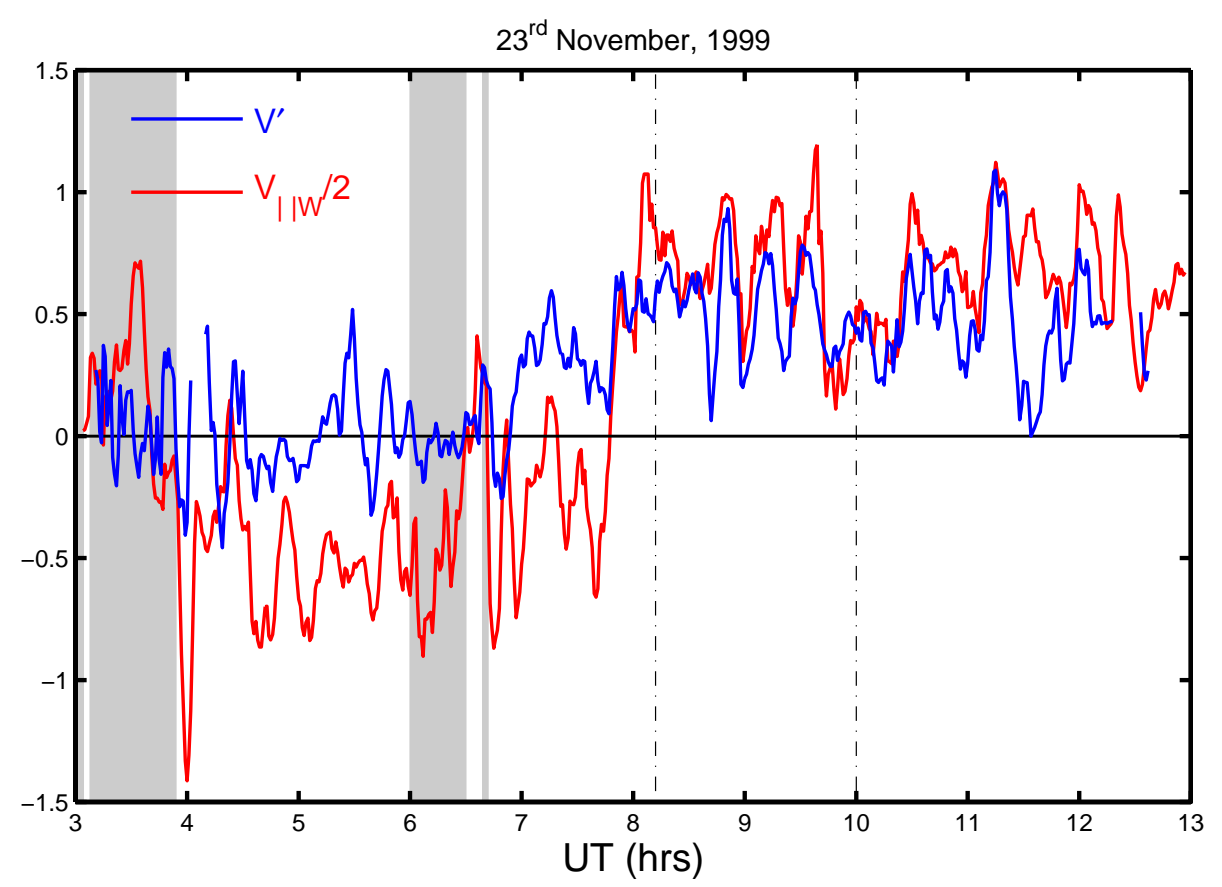

Fig. 13. (Blue) Variations of the boundary-normal convection velocity in the boundary rest frame $V^{\prime}=V_{\perp N}-V_{B}$ (positive poleward into the polar cap). (Red) The westward convection velocity $V_{\| W}$ derived by combining $V_{1}$ and $V_{2}$ for the range gates immediately poleward of the open-closed boundary signature. Data are 5-point running means of 1-minute data. As in Fig. 3, areas shaded grey are northward IMF and the vertical dot-dashed lines mark the expansion/recovery phases of the larger substorm.

We have used the energy dispersion characteristics of cusp ions to distinguish between active merging gap segments of the open-closed boundary and non-reconnecting ("adiaroic") segments. Specifically the presence/absence of lower cut-off cusp ions of energy exceeding $1 \mathrm{keV}$ and differential energy flux exceeding a clearly detectable threshold of $10^{7} \mathrm{~cm}^{-2} \mathrm{~s}^{-1} \mathrm{sr}^{-1}$ was used to identify the existence/lack of ongoing local reconnection. For protons propagating over a typical field-aligned distance from the X-line to the ionosphere of $20 R_{E}$, such ions are only seen on field lines that were reconnected within the past 5 minutes (so for a typical convection speed of $1 \mathrm{kms}^{-1}$, the satellite is within $300 \mathrm{~km}$ of an active merging gap). The similarity of when and where the radar and the satellites detected ongoing reconnection validates this technique.

The detection of the reconnection rate using the radar is described. Although the open-closed boundary is normally quite close to being L-shell aligned, significantly larger orientation angles are found and these can introduce significant errors if the east-west flow along the boundary is large. The flow across the inferred OCB in its own rest frame, $V^{\prime}$, has been computed at the MLT observed by EISCAT and gives a measure of the magnetopause reconnection rate. The radar saw ongoing reconnection over the MLT range 09:30-15:30. The data reveal a relatively stable reconnection merging gap, giving a broad inflow into the polar cap across the entire dayside.
The analysis shows that the reconnection merging gap covered a large part of the dayside on this day $(9<$ MLT $<15)$. This means that the entire dayside auroral oval expands equatorward in response to the enhanced magnetopause reconnection and also relaxed back poleward in the substorm expansion/recovery phases. These inferred large-scale motions of the OCB were seen in most detail by EISCAT, but there were sufficient DMSP passes for us to show that similar motions took place at other MLTs throughout the dayside. Thus the satellite data show that the boundary motions detected by EISCAT covered most of the dayside and were not restricted to a small range of MLTs around the radar. The motions have been shown to be consistent with unbalanced reconnection rates, with the dayside OCB eroding equatorward when the IMF points southward during substorm growth phases and relaxing back poleward during the subsequent expansion and recovery phases. This poleward retreat during the expansion phase was faster if the IMF is northward than when the magnetopause reconnection voltage remained high because the IMF continued to point southward.

Acknowledgements. The authors are grateful to the staff of the EISCAT Scientific Association for their support and the provision of the EISCAT radars. EISCAT is a collaboration of research Councils of the UK, France, Germany, Norway, Sweden, Finland, Japan and China. We also thank WDC, Kyoto for provision of the AL index, Phillips Laboratory and Johns Hopkins University for provision of the DMSP particle spectrograms and the teams of the magnetometers and solar wind instruments on board the ACE and Wind spacecraft for the provision of the interplanetary data. The UK authors 
of this paper are supported by PPARC, the Norwegian scientists by the Norwegian Research Council and AFOSR task 2311AS.

Topical Editor T. Pulkkinen thanks P. E. Sandholt and another referee for their help in evaluating this paper.

\section{References}

Akasofu, S.-I., Meng, C.-I., and Makita, K.: Changes of the size of the open field line region during substorms, Planet. Space Sci., 40, 1513-1524, 1992.

Aparicio, B., Thelin, B., and Lundin, R.: The polar cusp from a particle point of view: a statistical study based on Viking data, J. Geophys. Res., 96, 14 023-14 031, 1991.

Aubry, M. P., Russell, C. T., and Kivelson, M. G.: Inward motion of the magnetopause before a substorm, J. Geophys. Res., 75, 7018-7031, 1970.

Burch, J. L.: Rate of erosion of dayside magnetic flux based on a quantitative study of the dependence of polar cusp latitude on the interplanetary magnetic field, Radio Sci., 8, 955-961, 1973.

Carbary, J. F. and Meng, C.-I.: Correlation of cusp width with $\mathrm{AE}(12)$ and Bz, Planet. Space Sci., 36, 157-161, 1988.

Cowley, S. W. H. and Lockwood, M.: Excitation and decay of solar wind-driven flows in the magnetosphere-ionosphere system, Ann. Geophys., 10, 103-115, 1992.

Cowley, S. W. H. and Lockwood, M.: Incoherent scatter radar observations related to magnetospheric dynamics, Adv. Space Res., 20 (4/5), 873-882, 1997.

Cowley, S. W. H., Morelli, J. P., and Lockwood, M.: Dependence of convective flows and particle precipitation in the high-latitude dayside ionosphere on the $\mathrm{X}$ and $\mathrm{Y}$ components of the interplanetary magnetic field, J. Geophys. Res., 96, 5557-5564, 1991a.

Cowley, S. W. H., Freeman, M. P., Lockwood, M., and Smith, M. F.: The ionospheric signature of flux transfer events, in: CLUSTER - dayside polar cusp, edited by: Barron, C. I., ESA SP-330, 105-112, European Space Agency Publications, Noordwijk, The Netherlands, 1991b.

Crooker, N. U. and Rich, F. J.: Lobe-cell convection as a summer phenomenon, J. Geophys. Res., 98, 13 403-13 407, 1993

Davies, J. A., Yeoman, T. K., Rae, I. J., Milan, S. E., Lester, M., Lockwood, M., and McWilliams, K. A.: Ground-based observations of the auroral zone and polar cap ionospheric responses to dayside transient reconnection, Ann. Geophys., 20, 781-794, 2002 ,

\section{SRef-ID: 1432-0576/ag/2002-20-781.}

Eather, R. H.: Polar cusp dynamics, J. Geophys. Res., 90, 15691576, 1985

Eather, R. H., Mende, S. B., and Weber, E. J.: Dayside aurora and relevance to substorm current systems and dayside merging, J. Geophys. Res., 84, 3339-3359, 1979.

Elphinstone, R. D., Murphree, J. S., Hearn, D. J., Cogger, L. L., Newell, P. T., and Vo, H.: Viking observations of the UV dayside aurora and their relation to DMSP particle boundary definitions, Ann. Geophys., 10, 815-826, 1992.

Escoubet, C. P., Smith, M. F., Fung, S. F., Anderson, P. C., Hoffman, R. A., Basinska, E. M., and Bosqued, J. M.: Staircase ion signature in the polar cusp: a case study, Geophys. Res. Lett., 19, 1735-1738, 1992.

Farrugia, C. J., Sandholt, P. E., Denig, W. F., and Torbert, R. B.: Observation of a correspondence between poleward-moving auroral forms and stepped cusp ion precipitation, J. Geophys. Res., 103, 9309-9315, 1998.
Fox, N. J., Lockwood, M., Cowley, S. W. H., Freeman, M. P., FriisChristensen, E., Milling, D. K., Pinnock, M., and Reeves, G. D.: EISCAT observations of unusual flows in the morning sector associated with weak substorm activity, Ann. Geophys., 12, 541553, 1994,

SRef-ID: 1432-0576/ag/1994-12-541.

Fox, N. J., Cowley, S. W. H., Davies, J. A., Greenwald, R. A., Lester, M., Lockwood, M., and Lühr, H.: Ionospheric ion and electron heating at the poleward boundary of a polewardexpanding substorm-disturbed region, J. Geophys. Res., 106, 12 845-12 862, 2001.

Frank, L. A. and Craven, J. D.: Imaging results from Dynamics Explorer 1, Rev. Geophys., 26, 249-283, 1988.

Freeman, M. P.: A unified model of the response of ionospheric convection to changes in the interplanetary magnetic field, J. Geophys. Res., 108(A1), 102, doi:10.1029/2002JA009385, 2003.

Freeman, M. P. and Southwood, D. J.: The effects of magnetospheric erosion on mid- and high-latitude ionospheric flows, Planet. Space Sci., 36, 509-522, 1988.

Freeman, M. P., Ruohoniemi, J. M., and Greenwald, R. A.: The determination of time-stationary two-dimensional convection patterns with single-station radar, J. Geophys. Res., 96, 15735 $15749,1991$.

Fujimoto, M., Mukai, T., Kwano, H., Nakamura, M., Nishida, A., Saito, Y., Yamamota, T., and Kokubun, S.: Structure of the low latitude boundary layer: A case study with Geotail data, J. Geophys. Res., 103, 2297-2308, 1998.

Greenwald, R. A., Baker, K. B., Ruohoniemi, J. M., Dudeney, J. R., Pinnock, M., Mattin, N., Leonard, J. M., and Lepping, R. P.: Simultaneous conjugate observations of dynamic variations in high-latitude dayside convection due to changes in IMF By, J. Geophys. Res., 95, 8057-8072, 1990.

Heelis, R. A., Hanson, W. B., and Burch, J. L.: Ion convection reversals in the dayside cleft, J. Geophys Res., 81, 3803-3809, 1976.

Horwitz, J. L. and Akasofu, S.-I.: The response of the dayside aurora to sharp northward and southward transitions of the interplanetary magnetic field and to magnetospheric substorms, J. Geophys. Res., 82, 2723-2734, 1977.

Jørgensen, T. S., Friis-Christensen, E., Wickwar, V. B., Kelly, J. D., Clauer, C. R., and Banks, P. M.: On the reversal from "sunward" to "antisunward" plasma convection in the dayside high latitude ionosphere, Geophys. Res. Lett., 1, 887-890, 1984.

Lester, M., Freeman, M. P., Southwood, D. J., Waldock, J. A., and Singer, H. J.: A study of the relationship between interplanetary parameters and large displacements of nightside polar-cap boundary, J. Geophys. Res., 95, 21 133-21 145, 1990.

Lockwood, M.: The location and characteristics of the reconnection X-line deduced from low-altitude satellite and ground-based observations: 1. Theory, J. Geophys. Res., 100, 21 791-21 802, 1995.

Lockwood, M.: The case for transient magnetopause reconnection, EOS, Trans. Am. Geophys. Union, 77(26), 246-250, 1996.

Lockwood, M.: The relationship of dayside auroral precipitations to the open-closed separatrix and the pattern of convective flow, J. Geophys. Res., 102, 17475-17487, 1997a.

Lockwood, M.: Energy and pitch angle dispersions of LLBL/cusp ions seen at middle altitudes: predictions by the open magnetosphere model, Ann. Geophys., 15 , 1501-1514, 1997b,

SRef-ID: 1432-0576/ag/1997-15-1501. 
Lockwood., M.: Identifying the open-closed field-line boundary, in: Polar-cap boundary Phenomena, edited by: Moen, J. Egeland, A., and Lockwood, M., NATO Advanced Study Institute Series, Kluwer Academic Press, Dordrecht, Vol. 509, 415-432, 1998.

Lockwood, M. and Cowley, S. W. H.: Ionospheric Convection and the substorm cycle, in: Substorms 1, Proceedings of the First International Conference on Substorms, ICS-1, edited by: Mattock, C., ESA-SP-335, European Space Agency Publications, Nordvijk, The Netherlands, 99-109, 1992.

Lockwood, M. and Davis, C. J.: The occurrence probability, width and number of steps of cusp precipitation for fully-pulsed reconnection at the dayside magnetopause, J. Geophys. Res. 100, 7627-7640, 1995.

Lockwood, M. and Davis, C. J.: On the longitudinal extent of magnetopause reconnection bursts, Ann. Geophys., 14, 865-878, 1996 ,

\section{SRef-ID: 1432-0576/ag/1996-14-865.}

Lockwood, M. and Moen, J.: Reconfiguration and closure of lobe flux by reconnection during northward IMF: evidence for signatures in cusp/cleft auroral emissions, Ann. Geophys., 17, 9961011, 1999,

\section{SRef-ID: 1432-0576/ag/1999-17-996.}

Lockwood, M. and Morley, S. K.: A numerical model of the ionospheric signatures of time-varying magnetic reconnection: I. Ionospheric convection, Ann. Geophys., 22, 73-91, 2004

SRef-ID: 1432-0576/ag/2004-22-73.

Lockwood, M. and Smith, M. F.: The variation of reconnection rate at the dayside magnetopause and cusp ion precipitation, J. Geophys. Res., 97, 14 841-14 847, 1992.

Lockwood, M. and Wild, M. N.: On the quasi-periodic nature of magnetopause flux transfer events, J. Geophys. Res., 98, 59355940, 1993.

Lockwood, M., Cowley, S. W. H., Todd, H., Willis, D. M., and Clauer, C. R.: Ion flows and heating at a contracting polar-cap boundary, Planet. Space Sci., 36, 1229-1253, 1988.

Lockwood, M., Sandholt, P. E., and Cowley, S. W. H.: Dayside auroral activity and momentum transfer from the solar wind, Geophys. Res. Lett., 16, 33-36, 1989a.

Lockwood, M., Sandholt, P. E., Cowley, S. W. H., and Oguti, T.: Interplanetary magnetic field control of dayside auroral activity and the transfer of momentum across the dayside magnetopause, Planet. Space Sci., 37, 1347-1365, 1989b.

Lockwood, M., Cowley, S. W. H., and Freeman, M. P.: The excitation of plasma convection in the high-latitude ionosphere, J. Geophys. Res., 95, 7961-7972, 1990.

Lockwood, M., Denig, W. F., Farmer, A. D., Davda, V. N., Cowley, S. W. H., and Lühr, H.: Ionospheric signatures of pulsed magnetic reconnection at the Earth's magnetopause, Nature, 361 (6411), 424-428, 1993a.

Lockwood, M., Moen, J., Cowley, S. W. H., Farmer, A. D., Løvhaug, U.-P., Lühr, H. and Davda, V. N.: Variability of dayside convection and motions of the cusp/cleft aurora, Geophys. Res. Lett., 20, 1011-1014, 1993 b.

Lockwood, M., Lanchester, B. S., Frey, H. , Throp, K., Morley, S. K., Milan, S. E., and Lester, M.: IMF Control of Cusp Proton Emission Intensity and Dayside Convection: implications for component and anti-parallel reconnection., Ann. Geophys., 21, 955-982, 2003,

SRef-ID: 1432-0576/ag/2003-21-955.

Lockwood, M., Davies, J. A., Moen, J., van Eyken, A. P., Oksavik, K., and McCrea, I. W.: Motion of the dayside polar cap boundary during substorm cycles: II. polar patch generation by pulses in the magnetopause reconnection rate, Ann. Geophys., 23, - , 2005.

McCrea, I. W., Lockwood, M., Moen, J., Pitout, F., Eglitis, P., Aylward, A. D., Cerisier, J.-C., Thorolfssen, A., and Milan, S. E.: ESR and EISCAT observations of the response of the cusp and cleft to IMF orientation changes, Ann. Geophys., 18, 1009-1026, 2000 ,

SRef-ID: 1432-0576/ag/2000-18-1009.

McWilliams, K. A., Yeoman, T. K., and Provan, G.: A statistical survey of dayside pulsed ionospheric flows as seen by the CUTLASS Finland HF radar, Ann. Geophys., 18, 445-453, 2000,

SRef-ID: 1432-0576/ag/2000-18-445.

Milan, S. E., Lester, M. E., Cowley, S. W. H., Oksavik, K., Brittnacher, M., Greenwald, R. A., Sofko, G., and Villain, J.-P.: Variation in polar cap area during two substorm cycles, Ann. Geophys., 21, 1121-1140, 2003,

SRef-ID: 1432-0576/ag/2003-21-1121.

Moen, J., Sandholt, P. E., Lockwood, M., Denig, W. F., Løvhaug, U.-P., Lybekk, B., Egeland, A., Opsvik, D., and FriisChristensen, E.: Events of enhanced convection and related dayside auroral activity, J. Geophys. Res. 100, 23 917-23 934, 1995.

Moen, J., Lockwood, M., Sandholt, P. E., Løvhaug, U.-P. , Denig, W. F., van Eyken, A. P., and Egeland, A.: Variability of dayside high-latitude convection associated with a sequence of auroral transients, J. Atmos. Terr. Phys., 58, 85-96, 1996.

Moen, J., Lockwood, M., Oksavik, K., Carlson, H. C., Denig, W. F., van Eyken, A. P., and McCrea, I. W.: The dynamics and relationships of precipitation, temperature and convection boundaries in the dayside auroral ionosphere, Ann. Geophys., 22, 1973-1987, 2004,

SRef-ID: 1432-0576/ag/2004-22-1973.

Morley, S. K. and Lockwood, M.: The effect of reconnection rate pulse height on cusp ion steps, Ann. Geophys., 21, 947-953, 2003,

SRef-ID: 1432-0576/ag/2003-21-947.

Moses, J. J., Siscoe, G. L., Heelis, R. A., and Winningham, J. D.: Polar cap deflation during magnetospheric substorms, J. Geophys. Res., 94, 3785-3789, 1989.

Newell, P. T. and Meng, C.-I.: Ion acceleration at the equatorward edge of the cusp: low altitude observations of patchy merging, Geophys. Res. Lett, 18, 1829-1832, 1991.

Nishida, A., Mukai, T., Hayakawa, H., Matsuoka, A., Tsuruda, K., Kaya, N., and Fukunishi, H.: Unexpected features of the ion precipitation in the so-called cleft/low-latitude boundary layer region: Association with sunward convection and occurrence on open field lines, J. Geophys. Res., 98, 11 161-11 176, 1993.

Oksavik, K., Søraas, F., Moen, J., and Burke, W. J.: Optical and particle signatures of magnetospheric boundary layers near magnetic noon: Satellite and ground-based observations, J. Geophys. Res., 105, 27 555-27 568, 2000.

Oksavik, K., Søraas, F., Moen, J., Pfaff, R., Davies, J. A., and Lester, M.: Simultaneous optical, CUTLASS HF radar, and FAST spacecraft observations: Signatures of boundary layer processes in the cusp, Ann. Geophys., 22, 511-525, 2004,

SRef-ID: 1432-0576/ag/2004-22-511.

Onsager, T. G., Scudder, J. D., Lockwood, M., and Russell, C. T.: Reconnection at the High-Latitude Magnetopause During Northward IMF Conditions, J. Geophys. Res., 106, 25 467-25 488, 2001.

Pinnock, M., Rodger, A. S., Dudeney, J. R., Baker, K. B., Newell, P. T., Greenwald, R. A., and Greenspan, M. E.: Observations of an enhanced convection channel in the cusp ionosphere, J. Geophys. 
Res., 98, 3767-3776, 1993.

Pinnock, M., Rodger, A. S., Dudeney, J. R., Rich, F., and Baker, K. B.: High spatial and temporal resolution observations of the ionospheric cusp, Ann. Geophys., 13, 919-925, 1995,

SRef-ID: 1432-0576/ag/1995-13-919.

Reiff, P. H.: Sunward convection in both polar caps, J. Geophys. Res., 87, 5976-5980, 1982.

Rezhenov, B. V., Vorobjev, V. G., and Feldstein, Y.-I.: The interplanetary magnetic field Bz component influence on the geomagnetic field and on auroral dynamics, Planet. Space Sci., 27, 699716, 1979

Richard, R. L., Walker, R. J., and Ashour-Abdalla, M.: The population of the magnetosphere by solar wind ions when the interplanetary magnetic field is northward, Geophys. Res. Lett. 21, 2455-2458, 1994.

Sandholt, P. E.: IMF control of the polar cusp and cleft auroras, Adv. Space Res., 8, (9)21-(9)34, 1988.

Sandholt, P. E., Egeland, A., Deehr, C. S., Sivjee, G. C., and Romick, G. J.: Effects of interplanetary magnetic field and magnetic substorm variations on the dayside aurora, Planet. Space Sci., 31, 1345-1362, 1983.
Sandholt, P. E., Farrugia, C. J., Moen, J., and Cowley, S. W. H.: Dayside auroral configurations: Responses to southward and northward rotations of the interplanetary magnetic field, J. Geophys. Res., 103(A9), 20 279-20 296, 1998.

Siscoe, G. L. and Huang, T. S.: Polar cap inflation and deflation, Geophys. Res. Lett., 90, 543-547, 1985.

Song, P. and Russell, C. T.: Model of the formation of the lowlatitude boundary layer for strongly northward interplanetary magnetic field, J. Geophys. Res., 97, 1411-1420, 1992.

Vorobjev, V. G., Gustafsson, G., Starkov, G. V., Feldstein, Y. I., and Shevnina, N. F: Dynamics of day and night aurorae during substorms, Planet Space Sci., 23, 269-278, 1975.

Williams, P. J. S., Etemadi, W., McCrea, I. W., and Todd, H.: Errors due to random noise in velocity measurement using incoherentscatter radar, Ann. Geophys., 14, 1480-1486, 1996,

SRef-ID: 1432-0576/ag/1996-14-1480. 